\title{
Maxwell hybrid nanoliquid flow over vertical cone with Cattaneo - Christov heat flux and convective boundary condition
}

\author{
Sudarsana Reddy ${ }^{1}$, P. Sreedevi ${ }^{1}$, and Ali Chamkha ${ }^{2}$ \\ ${ }^{1}$ Rajeev Gandhi Memorial College of Engineering \& Technology \\ ${ }^{2}$ Duy Tan University
}

July 13, 2020

\begin{abstract}
This article presents to evaluating the sway of thermal radiation and chemical reaction on MHD flow of Ag/SWCNT - Water based Maxwell hybrid nanoliquid over a vertical cone by considering Cattaneo - Christov heat flux, convective boundary condition and suction parameter. By using appropriate transformations the nonlinear partial differential equations are converted into ordinary differential equations. The governing dimensionless equations are solved by using an optimized and extensively validated Finite element method. The sway of dissimilar parameter on hydrodynamic, thermal and solutal boundary layer is perceived and the results are laid out graphically. Additionally, the values of skin - friction coefficient, Nusselt number and Sherwood numbers are authorized for different values of pertinent parameters and results are demonstrated in tabular form. Comparison of the present problem results with existing results shows good agreement. The key observations are summarized as the velocity grows with (1), Temperature increases for Biot number (Bi) and Skin - friction coefficient, Sherwood number declines, nevertheless Nusselt number escalates as values of Deborah number $(\alpha)$ improves.
\end{abstract}

\begin{abstract}
:
This article presents to evaluating the sway of thermal radiation and chemical reaction on MHD flow of $\mathrm{Ag} / \mathrm{SWCNT}$ - Water based Maxwell hybrid nanoliquid over a vertical cone by considering Cattaneo - Christov heat flux, convective boundary condition and suction parameter. By using appropriate transformations the nonlinear partial differential equations are converted into ordinary differential equations. The governing dimensionless equations are solved by using an optimized and extensively validated Finite element method. The sway of dissimilar parameter on hydrodynamic, thermal and solutal boundary layer is perceived and the results are laid out graphically. Additionally, the values of skin - friction coefficient, Nusselt number and Sherwood numbers are authorized for different values of pertinent parameters and results are demonstrated in tabular form. Comparison of the present problem results with existing results shows good agreement. The key observations are summarized as the velocity grows with $(\phi 1)$, Temperature increases for Biot number (Bi) and Skin - friction coefficient, Sherwood number declines, nevertheless Nusselt number escalates as values of Deborah number $(\alpha)$ improves.
\end{abstract}

Keywords: Cattaneo - Christov heat flux; Convective boundary condition; Suction parameter; $A g / S W C N T$ Water Maxwell hybrid nanoliquid; FEM.

\section{Introduction}

Nanoliquids are one new kind of heat transfer fluid containing a small quantity of nanosized particles $(<100$ $\mathrm{nm}$ ) that are uniformly suspended in a fluids. Nanoliquids play an important role for various heat transfer applications. They are used to give better thermal performance than natural convectional fluids due to the presence of suspended nanoparticles with high thermal conductivity. Furthermore, several researchers 
reported that enhancement in the heat transfer rate with the use of various nanoliquids in various application compared to conventional fluids. Choi et al. [1] presented the fundamental limits of convectional heat conduction model by suspending nanoliquids and measured that high thermal conductivity is anomalously greater than theoretical predictions and which are nonlinear with nanotube loadings. Nabati Shoghl et al. [2] investigated thermophysical properties of water based nanoliquid and results showed that enhancement in electrical conductivity and viscosity of base fluid by suspending nanoparticles. Sundar et al. [3] demonstrated experimental study of thermal conductivity and viscosity of nanoliquids with nano diamond particles, however, the density and specific heat were estimated theoretically and reported that at 1.0 vol \% the thermal conductivity enhancements of $12.7 \%$ and $22.8 \%$, at 1.0 vol\% the viscosity enhancement of 1.57 times and 1.8 times were observed at temperatures of $293 \mathrm{~K}$ and $333 \mathrm{~K}$ than the general liquid. Many experimental and theoretical studies have been focused on enhancement of thermal conductivity of different nanoliquids by several authors [4-7]. Patil et al. [8] inspected non-linear mixed convection flow and heat transfer analysis of nanoliquid over vertical cone and found that rates of heat transfer is low for the nanoliquid compared to the ordinary mixture of liquid. Ramzan et al. [9] perceived the impact of thermal radiation parameter on steady flow, heat and mass characteristics and entropy analysis of nanoliquid made up of carbon nanotubes over a vertical cone and detected deterioration in the rates of velocity with improving values of bio-convection Rayleigh number.

To know the knowledge of heat exchange mechanism in applications of nanoliquid in various situations, heat conduction model has been proposed by Fourier. Later, Cattaneo presented the modified Fourier's law for heat conduction in an inflexible body by considering thermal relaxation time, which is called as Maxwell - Cattaneo law. After that, Christov focused to the theory of nanoliquids by employing Oldroyd upper - convected derivative rather than Maxwell time derivative while dealing with Cattaneo type theory of nanoliquid. Several authors described MHD boundary layer flow, heat and mass transfer analysis of different nanoliquids by using Cattaneo - Christov heat flux model. Ahmad Khan et al. [10] demonstrated in their work on heat and mass transfer flow in upper - convected Maxwell fluid over an exponentially stretching surface with Cattaneo - Christov heat flux model and found that the fluid velocity is impedes as the thermal relaxation time values rises. Ghalambaz et al. [11] studied natural convection flow of $\mathrm{Al} 2 \mathrm{O} 3-$ water nanoliquids over a vertical cone by considering variable thermal conductivity by using Tiwari-Das model. Heat and mass transfer analysis of Burgers nanoliquid flow through stretched sheet with Cattaneo - Christov heat flux model examined by Waqas et al. [12]. Hayat et al. [13] analyzed three dimensional rotating flow of Jeffery fluid over stretching sheet with Cattaneo - Christov heat flux model and noted that retardation in velocity sketches with rising values of ratio of relaxation parameter. The sway of Catteneo - Christov heat flux on mass and heat transfer analysis of various nanoliquids over different geometries instead of conventional Fourier's law deliberated by several authors [14 - 17]. Saleem et al. [18] cognized the impact of Cattaneo - Christov heat flux and heat generation/absorption on heat and mass transfer analysis over stretching sheet with optimal homotopy analysis method. Khan et al. [19] probed that the sway of homogeneous-heterogeneous chemical reaction on heat and fluid flow of Sisko fluid over bidirectional stretching sheet and conclude that fluid temperature and velocity is decreasing function with higher values of thermal relaxation parameter. Ali et al. [20] demonstrated MHD boundary layer flow of Casson nanoliquid over a cone, wedge and plate by considering Cattaneo - Christov heat flux model with nonlinear radiation effects and variable source/sink and found that heat transfer performance and local Nusselt number enhances with step-up values of thermal relaxation parameter over a wedge compared with flows over a plate and cone. Jayachandra babu et al. [21] studied MHD flow, mass and heat transfer analysis over three geometries (plate, wedge, cone) by inspecting Cattaneo - Christov heat flux model with the impact of thermophoresis and Brownian motion and detected that Sherwood number and Nusselt number highly influenced over cone by the thermal relaxation parameter. Mamatha et al. [22] demonstrated theoretically unsteady, MHD flow on heat and mass transfer characteristics by considering thermal radiation and Cattaneo-Christov heat flux by dispersing grapheme nanoparticles in dusty fluids. Iqbal et al. [23] analyzed the influence of Cattaneo Christov mass and heat flux on nanoliquid flow over circular cone.

Recently, so many authors interested to describes the behavior of hybrid nanoliquid as a part of new gen- 
eration of engine oil. These nanoliquids has several application in MRI scanning, optical modulators etc., Behseresht et al. [24] explored thermo physical properties of nanoliquid filled with porous media over a vertical cone. Nadeem et al. [25] studied third Grade fluid flow over a rotating vertical cone in the presence of thermophoresis and Brownian motion by using Homotopy analysis method. Reddy et al. [26] studied MHD boundary layer flow, mass and heat transfer characteristics of nanoliquids filled with Al2O3 and Ag nanoparticles over Vertical cone and concluded that fluid velocity rises, whereas the temperature and concentration decelerates when the values of $(\phi)$ improves. The impact of thermophoresis and Brownian motion on heat and mass transfer analysis flow of Jeffery, Maxwell and Oldroyd-B nanoliquids over a cone in the presence of non-uniform heat source/sink was explored by Raju et al. [27] and concluded that impact of magnetic field is more influenced in Maxwell nanoliquid than Jerry and Oldroyd-B nanoliquids. Siddiqa et al. [28 - 29] proposed bio convection mass and heat transfer analysis of nanoliquids over vertical wavy cone filled with gyrotactic microorganisms. Reddy et al. [30] probed the sway of chemical reaction on heat and mass transfer flow of nanoliquid over a vertical cone by using Buongiorno model and found that temperature and concentration sketches are escalated as the values of thermophoresis rises. Oyelakin et al. [31] perceived mass and heat transfer properties of Casson nanoliquid flow over a vertical cone with Cattaneo-Christov heat flux model under the convective boundary condition. Dinarvand et al. [32] discussed MHD convective boundary layer flow, mass and heat transfer analysis of water - based nanofluid suspended with Copper, alumina and titania nanoparticles over rotating down point cone by using Tiwari-Das model. Sreedevi et al. [33] analyzed the sway of chemical reaction and suction/injection on MHD boundary layer flow, mass and heat transfer characteristics of water - based nanoliquid containing SWCNT and MWCNT nanoparticles over a vertical cone with convective boundary condition and found that all values of rates of mass transfer, rates of heat transfer and velocity rates escalates with improving values of Biot number. Recently, several authors [34-38] studied the impact of various pertinent parameters on boundary layer flow, mass and heat transfer analysis of different hybrid nanoliquids over several geometries.

Recently, several articles investigate the fluid flow, mass and heat transfer characteristics of different nanoliquids over several geometries. No studies have been analyzed to examine mass and heat analysis of Maxwell hybrid nanoliquid over a vertical cone with Catteneo - Christov heat flux model under the convective boundary condition. Hence, we examine the sway of different parameters on Maxwell hybrid nanoliquid flow, heat and mass transfer analysis over a vertical cone and calculated local skin - friction coefficient, Sherwood and Nusselt numbers.

\section{Mathematical Analysis of the problem}

Consider two dimensional, steady, MHD boundary layer heat and mass transfer characteristics of $A g / S W C N T$ - Water based Maxwell hybrid nanoliquid over a vertical cone under convective boundary condition with suction as demonstrated in Fig. 1. The $A g / S W C N T$ - Water based Maxwell hybrid nanoliquid flow is chosen as the x-axis over the surface of the vertical cone. An external magnetic field $B_{0}$ is applied along the y-axis. It is assumed that $T_{w}$ to be determined, as the result of convective heating process which is characterized by a temperature $T_{f}$ and heat transfer coefficient $h_{f}$ and $C_{w}$ is the nanoparticle volume fraction at the surface of the cone and $T_{\infty}$ and $\mathrm{C}_{\infty}$ are the temperature and nanoparticle volume fraction of the ambient fluid, respectively. Under the above considerations, the governing equations describing the momentum, energy and concentration in the presence of thermal radiation and chemical reaction as follows:

$\frac{\partial u}{\partial x}+\frac{\partial v}{\partial y}=0(1)$

$u \frac{\partial u}{\partial x}+v \frac{\partial u}{\partial y}+\lambda_{1}\left(u^{2} \frac{\partial^{2} u}{\partial x^{2}}+v^{2} \frac{\partial^{2} u}{\partial y^{2}}+2 u v \frac{\partial^{2} u}{\partial x \partial y}\right)=\nu_{\mathrm{hnf}} \frac{\partial^{2} u}{\partial y^{2}}+\mathrm{g}\left[\beta\left(T-T_{\infty}\right)-\beta^{*}\left(C-C_{\infty}\right)\right] \grave{\partial} \sigma \lambda-\frac{\sigma B_{0}{ }^{2}}{}$

english $\rho_{\mathrm{hnf}} u(2)$

$u \frac{\partial T}{\partial x}+v \frac{\partial T}{\partial y}+\lambda_{2}\left(u \frac{\partial u}{\partial x} \frac{\partial T}{\partial x}+v \frac{\partial v}{\partial y} \frac{\partial T}{\partial y}+u \frac{\partial v}{\partial x} \frac{\partial T}{\partial y}+v \frac{\partial u}{\partial y} \frac{\partial T}{\partial x}+2 u v \frac{\partial^{2} T}{\partial x \partial y}+u^{2} \frac{\partial^{2} T}{\partial x^{2}}+v^{2} \frac{\partial^{2} T}{\partial y^{2}}\right)=\frac{k_{\mathrm{hnf}}}{\left(\rho C_{p}\right)_{\mathrm{hnf}}} \frac{\partial^{2} T}{\partial y^{2}}-$ $\frac{1}{\left(\rho C_{p}\right)_{\mathrm{nhf}}} \frac{\partial q_{r}}{\partial y}(3)$

$u \frac{\partial C}{\partial x}+v \frac{\partial C}{\partial y}=D_{B} \frac{\partial^{2} C}{\partial y^{2}}-C_{1}\left(C-C_{\infty}\right)(4)$ 
The following physical boundary conditions are

$u=0, \quad v=v_{w}, \quad-k \frac{\partial T}{\partial y}=h_{f}\left(T_{f}-T\right), \quad C=C_{w}$ at $y=0(5)$

$u \rightarrow 0, \quad T \rightarrow T_{\infty}, C \rightarrow C_{\infty}$ at $y \rightarrow \infty(6)$

The subsequent similarity transformations are presented to streamline the mathematical study of the problem $u=a x f^{\prime}(\eta), \quad v=-\sqrt{a v_{f}} \mathrm{f}(\eta), \quad \eta=\sqrt{\frac{a}{v_{f}}} y, \quad \theta(\eta)=\frac{T-T_{\infty}}{T_{f}-T_{\infty}}, S(\eta)=\frac{\phi-\phi_{\infty}}{\phi_{w}-\phi_{\infty}}(7)$

By utilizing Rosseland estimation for radiation, the radiative heat flux $q_{r}$ is demarcated as

$q_{r}=-\frac{4 \sigma^{*}}{3 K^{*}} \frac{\partial T^{4}}{\partial y}(8)$

After simplification using Taylor's series expansion, we get

$q_{r}=-\frac{16 \sigma^{*} T^{3}}{3 K^{*}} \frac{\partial T}{\partial y}(9)$

The transformed equations are

$f^{\prime \prime \prime}+\frac{A_{2}}{A_{1}} \mathrm{f} f^{\prime \prime}-\frac{A_{2}}{A_{1}}\left(f^{\prime}\right)^{2}-\alpha A_{1}\left[f^{2} f^{\prime \prime \prime}-2 f f^{\prime} f^{\prime \prime}\right]-A_{1} \mathrm{M} f^{\prime}+A_{1}[\theta-N r S] \operatorname{Cos} \lambda=0(10)$

$\left(1+A_{4} R\right) \theta^{\prime \prime}-\operatorname{Pr} \quad \frac{A_{3}}{A_{4}} \mathrm{f} \theta^{\prime}-\operatorname{Pr} \beta A_{3}\left(f^{2} \theta^{\prime \prime}+f f^{\prime} \theta^{\prime}\right)=0(11)$

$S^{\prime \prime}-S c f S^{\prime}-C_{r} S c S=0(12)$

The associated converted boundary conditions are

$\eta=0, \quad f=V 0, \quad f^{\prime}=1, \quad \theta^{\prime}(0)=-\operatorname{Bi}(1-\theta(0)), \quad S=1(13)$

$\eta \longrightarrow \infty, \quad \mathrm{f}^{\prime}=0, \quad \theta=0, \quad S=0$.

The associated non-dimensional parameters are defined as

$\operatorname{Pr}=\frac{v_{f}}{\alpha_{f}}, \beta=\lambda_{2} a, M=\frac{\sigma B_{0}^{2}}{\rho a}, \quad \alpha=\lambda_{1} a$,

$S c=\frac{v_{f}}{D_{B}}, C_{r}=\frac{C_{1}}{a}, \mathrm{R}=\frac{16 T_{\infty}^{3} \sigma^{*}}{3 k^{*} k_{f}}, V 0=\frac{v_{w}}{\sqrt{a v_{f}}}, B i=\frac{h_{f}}{\mathrm{k}}\left(\frac{\nu_{f}}{a}\right)^{1 / 2}$.

$A_{1}=\frac{1}{\left(1-\phi_{1}\right)^{2.5}\left(1-\phi_{2}\right)^{2.5}}, A_{2}=\left(1-\phi_{2}\right)\left[\left(1-\phi_{1}\right)+\phi_{1}\left(\frac{\rho_{s 1}}{\rho_{f}}\right)+\phi_{2}\left(\frac{\rho_{s 2}}{\rho_{f}}\right)\right]$,

$A_{3}=\left(1-\phi_{2}\right)\left[\left(1-\phi_{1}\right)+\phi_{1}\left(\frac{\left(\rho c_{p}\right)_{s 1}}{\left(\rho c_{p}\right)_{f}}\right)+\phi_{2}\left(\frac{\left(\rho c_{p}\right)_{s 2}}{\left(\rho c_{p}\right)_{f}}\right)\right], \quad A_{4}=\frac{k_{\mathrm{hnf}}}{k_{f}}$,

The density $\rho_{\mathrm{hnf}}$, thermal conductivity $k_{\mathrm{hnf}}$, dynamic viscosity $\mu_{\mathrm{hnf}}$, and heat capacitance $\left(\rho c_{p}\right)_{\mathrm{hnf}}$ of the hybrid nanoliquid are specified by:

$\mu_{\mathrm{hnf}}=\frac{\mu_{f}}{\left(1-\phi_{1}\right)^{2.5}\left(1-\phi_{2}\right)^{2.5}}, \rho_{\mathrm{hnf}}=\left(1-\varphi_{2}\right)\left[\left(1-\varphi_{1}\right) \rho_{f}+\varphi_{1} \rho_{s 1}\right]+\varphi_{2} \rho_{s 2}$,

$\left(\rho c_{p}\right)_{\mathrm{hnf}}=\left(1-\varphi_{2}\right)\left[\left(1-\varphi_{1}\right)\left(\rho c_{p}\right)_{f}+\varphi_{1}\left(\rho c_{p}\right)_{s 1}\right]+\varphi_{2}\left(\rho c_{p}\right)_{s 2}$

$k_{\mathrm{hnf}}=k_{\mathrm{nf}} *\left(\frac{k_{s 2}+2 k_{\mathrm{nf}}-2 \varphi_{2}\left(k_{\mathrm{nf}}-k_{s 2}\right)}{k_{s 2}+2 k_{\mathrm{nf}}+2 \varphi_{2}\left(k_{\mathrm{nf}}-k_{s 2}\right)}\right)$, where $k_{\mathrm{nf}}=k_{f} *\left(\frac{k_{s 1}+2 k_{f}-2 \varphi_{1}\left(k_{f}-k_{s 1}\right)}{k_{s 1}+2 k_{f}+2 \varphi_{1}\left(k_{f}-k_{s 1}\right)}\right)$.

The another object of this problem is to calculate skin - friction coefficient $\left(C_{f}\right)$, Nusselt number $\left(\mathrm{Nu}_{x}\right)$ and Sherwood number $\left(\mathrm{Sh}_{x}\right)$ and are given as

$C_{\mathrm{fx}}=\frac{\tau_{w}}{\rho U_{w}^{2}}, N u_{x}=\frac{x q_{w}}{k_{f}\left(T_{w}-T_{\infty}\right)}, \mathrm{S} h_{x}=\frac{x q_{m}}{D_{B}\left(C_{w}-C_{\infty}\right)}($

Where,

$\tau_{w}=\mu_{\mathrm{hnf}}(1+\alpha)\left(\frac{\partial u}{\partial y}\right)_{y=0}, q_{w}=-\left.k_{\mathrm{hnf}} \frac{\partial T}{\partial y}\right|_{y=0}, q_{m}=-\left.D_{B} \frac{\partial C}{\partial y}\right|_{y=0},(1$ 


\section{Numerical solution of the problem}

The variational Finite element process [39-42] is implemented to evaluate numerically above equations (10) - (12) with boundary conditions (13) - (14). The procedure of this method is as follows.

For the solution of system of non-linear ordinary differential equation (10) - (12) together with boundary conditions (13) - (14), first we assume that

$\frac{\delta \varphi}{\delta \eta}=h(16)$

The equations (10) to (12) then reduces to

$h^{\prime \prime}+\frac{A_{2}}{A_{1}} f \mathrm{~h}^{\prime}-\frac{A_{2}}{A_{1}} h^{2}-\alpha A_{1}\left[f^{2} h^{\prime \prime}-2 f h h^{\prime}\right]-A_{1} M h+A_{1}[\theta-N r S]=0(17)$

$\left(1+A_{4} R\right) \theta^{\prime \prime}-\operatorname{Pr} \frac{A_{3}}{A_{4}} \mathrm{f} \theta^{\prime}-\operatorname{Pr} \beta A_{3}\left[f^{2} \theta^{\prime \prime}+f h \theta^{\prime}\right]=0$ (18)

$S^{\prime \prime}-S c f S^{\prime}-S c C_{r} S=0(19)$

The boundary conditions take the form

$\eta=0, \quad f=V_{0}, \quad h=1, \quad \theta^{\prime}=-\operatorname{Bi}(1-\theta), \quad S=1(20)$

$\eta \rightarrow \infty, \quad h=0, \quad \theta=0, \quad S=0(21)$

\subsection{Variational formulation}

The variational form associated with Eqns. (17) to (19) over a typical linear element $\left(\eta_{e}, \eta_{e+1}\right)$ is given by

$\int_{\eta_{e}}^{\eta_{e+1}} w_{1}\left(\frac{\delta \varphi}{\delta \eta}-h\right) d \eta=0(22)$

$\int_{\eta_{e}}^{\eta_{e+1}} w_{2}\left(h^{\prime \prime}+\frac{A_{2}}{A_{1}} \mathrm{f} h^{\prime}-\frac{A_{2}}{A_{1}} h^{2}-\alpha A_{1}\left[f^{2} h^{\prime \prime}-2 f h h^{\prime}\right]-A_{1} M h+A_{1}[\theta-N r S]\right) d \eta=0$

$\int_{\eta_{e}}^{\eta_{e+1}} w_{3}\left(\left(1+A_{4} R\right) \theta^{\prime \prime}-\operatorname{Pr} \frac{A_{3}}{A_{4}} \mathrm{f} \theta^{\prime}-\operatorname{Pr} \beta A_{3}\left[f^{2} \theta^{\prime \prime}+f h \theta^{\prime}\right]\right) d \eta=0(24)$

$\int_{\eta_{e}}^{\eta_{e+1}} w_{4}\left(S^{\prime \prime}-S c f S^{\prime}-S c C_{r} \mathrm{~S}\right) d \eta=0(25)$

Where $w_{1}, w_{2}, w_{3}$, and $w_{4}$ are arbitrary test functions and may be viewed as the variations $\operatorname{in} f, h, \theta$, and $\mathrm{S}$ respectively.

\subsection{Finite- element formulation}

The finite-element model may be obtained from above equations by substituting finite-element approximations of the form

$f=\sum_{j=1}^{2} f_{j} \psi_{j}, \quad h=\sum_{j=1}^{2} h_{j} \psi_{j}, \theta=\sum_{j=1}^{2} \theta_{j} \psi_{j}, \phi=\sum_{j=1}^{2} \phi_{j} \psi_{j}$.

With, $\mathrm{w}_{1}=w_{2}=w_{3}=w_{4}=\psi_{i}, \quad(i=1,2,3)$.

Where $\psi_{i}$ are the shape functions for a typical element $\left(\eta_{e}, \eta_{e+1}\right)$ and are defined as

$$
\begin{gathered}
\psi_{1}^{e}=\frac{\left(\eta_{e+1}+\eta_{e}-2 \eta\right)\left(\eta_{e+1}-\eta\right)}{\left(\eta_{e+1}-\eta_{e}\right)^{2}}, \psi_{2}^{e}=\frac{4\left(\eta-\eta_{e}\right)\left(\eta_{e+1}-\eta\right)}{\left(\eta_{e+1}-\eta_{e}\right)^{2}}, \\
\psi_{3}^{e}=\frac{\left(\eta_{e+1}+\eta_{e}-2 \eta\right)\left(\eta-\eta_{e}\right)}{\left(\eta_{e+1}-\eta_{e}\right)^{2}}, \eta_{e} \leq \eta \leq \eta_{e+1} \cdot(27)
\end{gathered}
$$

The finite element model of the equations thus formed is given by 


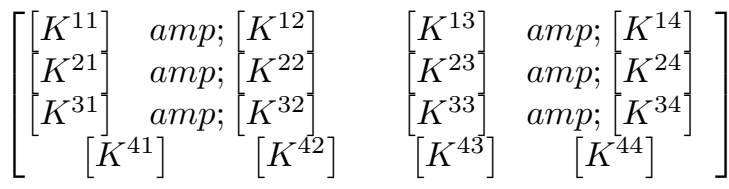

$$
\begin{aligned}
& {\left[\begin{array}{l}
f \\
h \\
\theta \\
\phi
\end{array}\right]=} \\
& {\left[\begin{array}{l}
\left\{r^{1}\right\} \\
r^{2} \\
r^{3} \\
\left\{r^{4}\right\}
\end{array}\right]}
\end{aligned}
$$

Where $\left[K^{\mathrm{mn}}\right]$ and $\left[r^{m}\right](m, n=1,2,3,4)$ are defined as

$$
\begin{aligned}
& K_{\mathrm{ij}}^{11}=\int_{\eta_{e}}^{\eta_{e+1}} \psi_{i} \frac{\partial \psi_{j}}{\partial \eta} \delta \eta, K_{\mathrm{ij}}^{12}=-\int_{\eta_{e}}^{\eta_{e+1}} \psi_{i} \psi_{j} \delta \eta, K_{\mathrm{ij}}{ }^{13}=K_{\mathrm{ij}}{ }^{14}=0, \mathrm{~K}_{\mathrm{ij}}{ }^{21}=0, \\
& K_{\mathrm{ij}}^{22}=\int_{\eta_{e}}^{\eta_{e+1}} \frac{\partial \psi_{i}}{\partial \eta} \frac{\partial \psi_{j}}{\partial \eta} d \eta+\frac{A_{2}}{A_{1}} f_{1} \int_{\eta_{e}}^{\eta_{e+1}} \psi_{i} \psi_{1} \psi_{j} d \eta+\frac{A_{2}}{A_{1}} f_{2} \int_{\eta_{e}}^{\eta_{e+1}} \psi_{i} \psi_{2} \psi_{j} d \eta-\frac{A_{2}}{A_{1}} h_{1} \int_{\eta_{e}}^{\eta_{e+1}} \psi_{i} \psi_{1} \psi_{j} d \eta- \\
& \frac{A_{2}}{A_{1}} h_{2} \int_{\eta_{e}}^{\eta_{e+1}} \psi_{i} \psi_{2} \psi_{j} d \eta-\beta A_{1} \int_{\eta_{e}}^{\eta_{e+1}}\left(\frac{\partial \psi_{i}}{\partial \eta}\right)^{2} \frac{\partial \psi_{i}}{\partial \eta} \frac{\partial \psi_{j}}{\partial \eta} d \eta+2 \beta A_{1} h_{1} \int_{\eta_{e}}^{\eta_{e+1}} \psi_{i} \psi_{1} \psi_{j} d \eta+2 \beta \mathrm{A}_{2} h_{2} \int_{\eta_{e}}^{\eta_{e+1}} \psi_{i} \psi_{2} \psi_{j} d \eta-A_{1} \mathrm{M} \int_{\eta_{e}}^{\eta_{e}} \\
& K_{\mathrm{ij}}^{23}=A_{1} \int_{\eta_{e}}^{\eta_{e+1}} \psi_{i} \psi_{j} d \eta, K_{\mathrm{ij}}{ }^{24}=-A_{1} \quad \operatorname{Nr}_{\eta_{e}}^{\eta_{e+1}} \psi_{i} \psi_{j} d \eta, \quad K_{\mathrm{ij}}{ }^{31}=0, \quad K_{\mathrm{ij}}{ }^{32}=0, \\
& K_{\mathrm{ij}}^{33}=\left(1+A_{4} R\right) \int_{\eta_{e}}^{\eta_{e+1}} \frac{\partial \psi_{i}}{\partial \eta} \frac{\partial \psi_{j}}{\partial \eta} \delta \eta-\operatorname{Pr} \frac{A_{3}}{A_{4}} f_{1} \int_{\eta_{e}}^{\eta_{e+1}} \psi_{i} \psi_{1} \frac{\partial \psi_{j}}{\partial \eta} \delta \eta-\operatorname{Pr} \frac{A_{3}}{A_{4}} f_{2} \int_{\eta_{e}}^{\eta_{e+1}} \psi_{i} \psi_{\vartheta} \frac{\partial \psi_{j}}{\partial \eta} \delta \eta- \\
& \operatorname{Pr} \gamma A_{3} h_{1} \int_{\eta_{e}}^{\eta_{e+1}} \psi_{i} \psi_{1} \frac{\partial \psi_{j}}{\partial \eta} \delta \eta-\operatorname{Pr} \gamma A_{3} h_{2} \int_{\eta_{e}}^{\eta_{e+1}} \psi_{i} \psi_{2} \frac{\partial \psi_{j}}{\partial \eta} d \eta, K_{\mathrm{ij}}^{34}=0 \\
& K_{\mathrm{ij}}^{41}=0, \mathrm{~K}_{\mathrm{ij}}^{42}=0, \mathrm{~K}_{\mathrm{ij}}^{43}=0 \text {, } \\
& K_{\mathrm{ij}}{ }^{44}=\int_{\eta_{e}}^{\eta_{e+1}} \frac{\partial \psi_{i}}{\partial \eta} \frac{\partial \psi_{j}}{\partial \eta} \delta \eta-S c f_{1} \int_{\eta_{e}}^{\eta_{e+1}} \psi_{i} \psi_{1} \frac{\partial \psi_{j}}{\partial \eta} \delta \eta-S c f_{2} \int_{\eta_{e}}^{\eta_{e+1}} \psi_{i} \psi_{2} \frac{\partial \psi_{j}}{\partial \eta} d \eta-S c C_{r} \int_{\eta_{e}}^{\eta_{e+1}} \psi_{\mathrm{\imath}} \psi_{j} \delta \eta . \\
& r_{i}^{2}=0, r_{i}^{2}=-\left(\psi_{i} \frac{d \psi_{i}}{\delta \eta}\right) \eta_{\eta_{e}}^{\eta_{e+1}}, r_{i}^{3}=-\left(\psi_{i} \frac{d \psi_{i}}{\delta \eta}\right) \eta_{\eta_{e}+1}^{\eta_{e}}, r_{i}^{4}=-\left(\psi_{i} \frac{d \psi_{i}}{\delta \eta}\right) \eta_{\eta_{e}}^{\eta_{e+1}} .
\end{aligned}
$$

\section{Results and Discussion}

The enormous and efficient Finite element method is used to solve the set of converted ordinary differential equations of physical problem. The concentration, temperature and velocity distributions of $\mathrm{Ag} / \mathrm{SWCNT}-$ Water based hybrid Maxwell nanoliquid for dissimilar values of pertinent parameters over a vertical cone under convective boundary conditions are illustrated in graphs from Figs. 2 - 25. The thermophysical properties of nanoparticles are shown in Table 1. Table 2 gives comparison between present results and existing results with good agreement.

The sway of magnetic parameter $(\mathrm{M})$ on Ag/SWCNT - Water based hybrid Maxwell nanoliquids concentration, temperature and velocity distributions are portrayed in Figs. $2-4$. Velocity sketches of Ag/SWCNT - Water based hybrid nanoliquid degenerates, whereas temperature and concentration sketches optimizes with upgrading values of $(\mathrm{M})$. This is because of the presence of magnetic field produces Lorentz force which resists the motion of fluid, it causes optimization in the fluids both temperature and concentration sketches.

Figs. 5 - 8 describes the outlines of Ag/SWCNT - Water base hybrid nanoliquid velocity for diverse values of $(\phi 1)$ and $(\phi 2)$. With developing values of $(\phi 1)$ the velocity outlines elaborates in entire fluid regime (Fig. 5). The Ag/SWCNT - Water base hybrid nanoliquid velocity outlines abatement, nevertheless, the concentration and temperature outlines enlarges with step up values of $(\phi 2)$.

Dissimilarity nature in velocity, temperature and concentration sketches for diverse values of Buoyancy parameter $(N r)$ is sketched in Figs. 9 - 11. The velocity sketches of $\mathrm{Ag} / \mathrm{SWCNT}$ - Water based hybrid 
nanoliquid deteriorates, however, the temperature and concentration sketches hike with boosting values of $(N r)$.

Figs. 12 - 14 are drawn to depict velocity, temperature and concentration outlines of Ag/SWCNT - Water base hybrid Maxwell nanoliquid for diverse values of Deborah number $(\alpha)$. It is perceived that the velocity portraits truncates with up surging values of $(\alpha)$, nevertheless, temperature and concentration portraits escalates as values of $\alpha$ rises.

The consequence of Biot number $(\mathrm{Bi})$ on velocity and temperature portraits of Ag/SWCNT - Water based Maxwell nanoliquid is cognized in Figs. 15 and 16. It is can be found that velocity portraits slackens with cumulating values of $(\mathrm{Bi})$, however, the temperature portraits maximizes with improving values of (Bi).

Fig. 17 characterized the sway of Radiation parameter (R) on temperature portraits of Ag/SWCNT - Water based Maxwell hybrid nanoliquid. It is examined that temperature outlines upturns with improving values of $(\mathrm{R})$. The influence of Prandtl number (Pr) on velocity and temperature outlines of Ag/SWCNT - Water based Maxwell nanoliquids are summarized in Figs. 18 and 19. It is concluded that velocity outlines maximizes with rising values of $(\mathrm{Pr})$, while, temperature outlines declines in entire fluid regime with improving values of $(\mathrm{Pr})$.

Variations in concentration sketches for dissimilar values of Schmidt number (Sc) are depicted in Fig. 20 in Ag/SWCNT - Water based Maxwell hybrid nanoliquid. The concentration sketches of Ag/SWCNT - Water based Maxwell hybrid nanoliquid waning with enlarged values of Sc. It can be seen that from the Fig. 21 that the concentration sketches degenerates with upturn values of chemical reaction parameter (Cr). The impact of Cattaneo Christov heat flux parameter $(\beta)$ on the scatterings of concentration is cognized in Fig. 22 and investigated that deterioration in concentration sketches as $(\beta)$ values rises.

Figs. 23 - 25 demonstrated that influence of suction parameter (V0) on velocity, temperature and concentration sketches of Ag/SWCNT - Water based Maxwell hybrid nanoliquid. It can be found that all the velocity, temperature and concentration sketches of Maxwell hybrid nanoliquid degenerates in entire fluid region with optimized values of (V0).

Table 3 reveals that values of $\left(-f^{\prime \prime}(0)\right),\left(-\theta^{\prime}(0)\right)$ and $\left(-S^{\prime}(0)\right)$ for dissimilar values of $M, \phi_{1}, \phi_{2}, N r, \alpha$ and Bi. Values of skin - friction coefficient, heat and mass transfer rates impedes with rising values of $(M)$. Values of non-dimensional rates of velocity augmented, whereas, rates of heat and mass transfer diminishes as the values of $\left(\phi_{1}\right)$ rises. Orderly, similar trend is happened in all skin - friction coefficient, Nusselt number and Sherwood number values with growing values of $\phi_{2}, N r, \alpha$ and $\mathrm{Bi}$.

The sway of $R, P r, S c, C r, \beta$ and $V 0$ on Skin - friction coefficient, Nusselt number and Sherwood number of Ag/SWCNT - Water based Maxwell hybrid nanoliquid is summarized in Table 4 . It can be found that from Table 4 values of Skin - friction coefficient and Sherwood number escalates with improving values of R, whereas, values of Nusselt number waning as $\mathrm{R}$ values improves. The reverse trend is happened in values of $\left(-f^{\prime \prime}(0)\right),\left(-\theta^{\prime}(0)\right)$ and $\left(-S^{\prime}(0)\right)$ with step up values of Pr. As the values of Sc \& Cr improves the values of $\left(-f^{\prime \prime}(0)\right),\left(-\theta^{\prime}(0)\right)$ and $\left(-S^{\prime}(0)\right)$ elaborates. Finally, Rate of non-dimensional heat and mass transfer enlarges, nevertheless, the skin - friction coefficient values diminish with developing values of V0.

\section{Conclusion}

This paper is focused on MHD steady flow of Ag/SWCNT - Water based Maxwell Hybrid nanoliquid heat and mass transfer characteristics over vertical cone with convective boundary. The results of the present problem are numerically calculated by using Finite element method and are depicted through graphs and tables. The important conclusions of this problem are summarized as follows:

1. Temperature and concentrations fields are intensifies, nevertheless the velocity fields declines with $\left(\phi_{1}\right)$.

2. Velocity, temperature and concentration profiles are deteriorated with suction parameter $(V 0)$. 
3. Skin - friction coefficient and Sherwood number truncates, however the Nusselt number improves as values of $(B i)$ rises.

4. Rate of velocity and mass transfer values maximizes, while, heat transfer values declines with boosting values of $(R)$.

5. Thickness of solutal boundary layer of Ag/SWCNT - Water based Maxwell nanoliquid with improving values $(\mathrm{Sc})$ and $(\mathrm{Cr})$.

\section{References:}

[1] Choi, S.U.S., Zhang, Z.G.,Yu, W., Lockwood, F.E., \& Grulke, E.A. (2001).Anomalous thermal conductivity enhancement in nano-tube suspensions. Appl. Phys,79, 2252- 2254.

[2] Nabati Shoghl, S., Jamali, J., \& Keshavarz Moraveji, M. (2016). Electrical conductivity, viscosity, and density of different nanoliquids: An experimental study. Experimental Thermal and Fluid Science, 74, 339346.

[3] Sundar, L. S., Hortiguela, M. J., Singh, M. K., \& Sousa, A. C. M. (2016). Thermal conductivity and viscosity of water based nanodiamond (ND) nanoliquids: An experimental study. International Communications in Heat and Mass Transfer, 76, 245-255.

[4] Begum, N., Siddiqa, S., \& Hossain, M. A. (2017). Nanoliquid bioconvection with variable thermophysical properties. Journal of Molecular Liquids, 231, 325-332.

[5] Ahmadi Nadooshan, A. (2017). An experimental correlation approach for predicting thermal conductivity of water-EG based nanoliquids of zinc oxide. Physica E: Low-Dimensional Systems and Nanostructures, 87, $15-19$.

[6] Bowers, J., Cao, H., Qiao, G., Li, Q., Zhang, G., Mura, E., \& Ding, Y. (2018). Flow and heat transfer behaviour of nanoliquids in microchannels. Progress in Natural Science: Materials International, 28(2), 225234.

[7] Doh, D.-H., Muthtamilselvan, M., Swathene, B., \& Ramya, E. (2020). Homogeneous and heterogeneous reactions in a nanofluid flow due to a rotating disk of variable thickness using HAM. Mathematics and Computers in Simulation, 168, 90-110.

[8] Patil, P. M., Shashikant, A., \& Hiremath, P. S. (2019). Diffusion of liquid hydrogen and oxygen in nonlinear mixed convection nanoliquid flow over vertical cone. International Journal of Hydrogen Energy, 44(31), 17061-17071.

[9] Ramzan, Mohammad, Howari, \& Chung. (2019). Entropy Analysis of Carbon Nanotubes Based Nanoliquid Flow Past a Vertical Cone with Thermal Radiation. Entropy, 21(7), 642.

[10] Ahmad Khan, J., Mustafa, M., Hayat, T., \& Alsaedi, A. (2015). Numerical Study of Cattaneo-Christov Heat Flux Model for Viscoelastic Flow Due to an Exponentially Stretching Surface. PLOS ONE, 10(9), e0137363.

[11] Ghalambaz, M., Behseresht, A., Behseresht, J., \& Chamkha, A. (2015). Effects of nanoparticles diameter and concentration on natural convection of the Al2O3-water nanoliquids considering variable thermal conductivity around a vertical cone in porous media. Advanced Powder Technology, 26(1), 224-235.

[12] Waqas, M., Hayat, T., Farooq, M., Shehzad, S. A., \& Alsaedi, A. (2016). Cattaneo-Christov heat flux model for flow of variable thermal conductivity generalized Burgers fluid. Journal of Molecular Liquids, 220, 642-648.

[13] Hayat, T., Qayyum, S., Imtiaz, M., \& Alsaedi, A. (2016). Three-dimensional rotating flow of Jeffrey fluid for Cattaneo-Christov heat flux model. AIP Advances, 6(2), 025012.

[14] Hayat, T., Khan, M. I., Farooq, M., Alsaedi, A., Waqas, M., \& Yasmeen, T. (2016). Impact of CattaneoChristov heat flux model in flow of variable thermal conductivity fluid over a variable thicked surface. 
International Journal of Heat and Mass Transfer, 99, 702-710.

[15] Hayat, T., Qayyum, S., Imtiaz, M., \& Alsaedi, A. (2017). Flow between two stretchable rotating disks with Cattaneo-Christov heat flux model. Results in Physics, 7, 126-133.

[16] Muhammad, N., Nadeem, S., \& Mustafa, T. (2017). Squeezed flow of a nanoliquid with CattaneoChristov heat and mass fluxes. Results in Physics, 7, 862-869.

[17] Hashim, \& Khan, M. (2017). On Cattaneo-Christov heat flux model for Carreau fluid flow over a slendering sheet. Results in Physics, 7, 310-319.

[18] Saleem, S., Awais, M., Nadeem, S., Sandeep, N., \& Mustafa, M. T. (2017). Theoretical analysis of upperconvected Maxwell fluid flow with Cattaneo-Christov heat flux model. Chinese Journal of Physics, 55(4), $1615-1625$.

[19] Khan, M., Ahmad, L., Khan, W. A., Alshomrani, A. S., Alzahrani, A. K., \& Alghamdi, M. S. (2017). A 3D Sisko fluid flow with Cattaneo-Christov heat flux model and heterogeneous-homogeneous reactions: A numerical study. Journal of Molecular Liquids, 238, 19-26.

[20] Ali, M. E., \& Sandeep, N. (2017). Cattaneo-Christov model for radiative heat transfer of magnetohydrodynamic Casson-ferrofluid: A numerical study. Results in Physics, 7, 21-30.

[21] Jayachandra Babu, M., Sandeep, N., \& Saleem, S. (2017). Free convective MHD Cattaneo-Christov flow over three different geometries with thermophoresis and Brownian motion. Alexandria Engineering Journal, 56(4), 659-669.

[22] Mamatha Upadhya, S., Raju, C. S. K., Mahesha, \& Saleem, S. (2018). Nonlinear unsteady convection on micro and nanoliquids with Cattaneo-Christov heat flux. Results in Physics, 9, 779-786.

[23] Iqbal, Khan, Mustafa, \& Ghaffari. (2019). Numerical Study of Natural Convection Flow of Nanoliquid Past a Circular Cone with Cattaneo-Christov Heat and Mass Flux Models. Symmetry, 11(11), 1363.

[24] Behseresht, A., Noghrehabadi, A., \& Ghalambaz, M. (2014). Natural-convection heat and mass transfer from a vertical cone in porous media filled with nanoliquids using the practical ranges of nanoliquids thermophysical properties. Chemical Engineering Research and Design, 92(3), 447-452.

[25] Nadeem, S., \& Saleem, S. (2015). Analytical study of third grade fluid over a rotating vertical cone in the presence of nanoparticles. International Journal of Heat and Mass Transfer, 85, 1041-1048.

[26] Reddy, P. S., \& Rao, K. V. S. (2015). MHD Natural Convection Heat and Mass Transfer of Al2O3Water and Ag-Water Nanoliquids over a Vertical Cone with Chemical Reaction. Procedia Engineering, 127, 476-484.

[27] Raju, C. S. K., Sandeep, N., \& Malvandi, A. (2016). Free convective heat and mass transfer of MHD non-Newtonian nanoliquids over a cone in the presence of non-uniform heat source/sink. Journal of Molecular Liquids, 221, 108-115.

[28] Siddiqa, S., Gul-e-Hina, Begum, N., Saleem, S., Hossain, M. A., \& Reddy Gorla, R. S. (2016). Numerical solutions of nanoliquid bioconvection due to gyrotactic microorganisms along a vertical wavy cone. International Journal of Heat and Mass Transfer, 101, 608-613.

[29] Siddiqa, S., Begum, N., \& Hossain, M. A. (2016). Radiation effects from an isothermal vertical wavy cone with variable fluid properties. Applied Mathematics and Computation, 289, 149-158.

[30] Reddy, P. S., \& Chamkha, A. (2017). Heat and mass transfer analysis in natural convection flow of nanoliquid over a vertical cone with chemical reaction. International Journal of Numerical Methods for Heat \& Fluid Flow, 27(1), 2-22. 
[31] Oyelakin, I. S., Mondal, S., \& Sibanda, P. (2017). Cattaneo-Christov Nanoliquid Flow and Heat Transfer with Variable Properties Over a Vertical Cone in a Porous Medium. International Journal of Applied and Computational Mathematics, 3(S1), 1019-1034.

[32] Dinarvand, S., \& Pop, I. (2017). Free-convective flow of copper/water nanoliquid about a rotating downpointing cone using Tiwari-Das nanoliquid scheme. Advanced Powder Technology, 28(3), 900-909.

[33] Sreedevi, P., Reddy, P. S., \& Chamkha, A. J. (2018). Magneto-hydrodynamics heat and mass transfer analysis of single and multi-wall carbon nanotubes over vertical cone with convective boundary condition. International Journal of Mechanical Sciences, 135, 646-655.

[34] Alirezaie, A., Saedodin, S., Esfe, M. H., \& Rostamian, S. H. (2017). Investigation of rheological behavior of MWCNT (COOH-functionalized)/MgO - Engine oil hybrid nanoliquids and modelling the results with artificial neural networks. Journal of Molecular Liquids, 241, 173-181.

[35] Maraj, E. N., Iqbal, Z., Azhar, E., \& Mehmood, Z. (2018). A comprehensive shape factor analysis using transportation of MoS2-SiO2/H2O inside an isothermal semi vertical inverted cone with porous boundary. Results in Physics, 8, 633-641.

[36] Huminic, G., \& Huminic, A. (2018). Heat transfer capability of the hybrid nanoliquids for heat transfer applications. Journal of Molecular Liquids, 272, 857-870.

[37] Ghadikolaei, S. S., Hosseinzadeh, K., \& Ganji, D. D. (2018). Investigation on ethylene glycol-water mixture fluid suspend by hybrid nanoparticles $(\mathrm{TiO} 2-\mathrm{CuO})$ over rotating cone with considering nanoparticles shape factor. Journal of Molecular Liquids, 272, 226-236.

[38] Gnaneswara Reddy, M., Sudha Rani, M. V. V. N. L., Ganesh Kumar, K., Prasannakumar, B. C., \& Lokesh, H. J. (2020). Hybrid dusty fluid flow through a Cattaneo-Christov heat flux model. Physica A: Statistical Mechanics and Its Applications, 123975.

[39] Sudarsan Reddy, P., Prasada Rao, DRV. (2012). Thermo-diffusion and diffusion -thermo effects on convective heat and mass transfer through a porous medium in a circular cylindrical annulus with quadratic density temperature variation- Finite element study. Journal of Applied Fluid Mechanics, 5, 139-144.

[40] Sreedevi, P., Sudarsana Reddy, P., \& Chamkha, A.J. (2017). Heat and mass transfer analysis of nanoliquid over linear and non- linear stretching surface with thermal radiation and chemical reaction. Powder Technology, 315, $194-204$.

[41] Prabhavathi, B., Sudarsana Reddy, P., \& Bhuvana Vijaya, R. (2018). Heat and mass transfer enhancement of SWCNTs and MWCNTs based Maxwell nanoliquid flow over a vertical cone with slip effects, Powder Technology, 340, 253 - 263

[42] Sudarsana Reddy, P., \& Chamkha, A.J. (2018). Heat and mass transfer characteristics of MHD threedimensional flow over a stretching sheet filled with water - based Alumina nanoliquid. International Journal of Numerical Methods for Heat and Fluid Flow, 28, $532-546$.

[43] I. Waini, A. Ishak, and I. Pop, Unsteady flow and heat transfer past a stretching/shrinking sheet in a hybrid nanoliquid, International Journal of Heat and Mass Transfer 136 (2019) 288-297. 


\section{Nomenclature}

$C_{f}$ Skin-friction coefficient Nb Brownian motion Parameter

$k_{f}$ Thermal conductivity of basefluid $N u_{x}$ Nusselt number

Nt Thermophoretic Parameter Re Local Reynolds number

$C_{\infty}$ Ambient fluid concentration $u_{\infty}$ Velocity of mainstream

$T_{w}$ Wall constant temperature $T_{\infty}$ Ambient temperature

$\mathrm{T}$ Fluid temperature C Fluid concentration

$q_{w} \quad$ Wall heat flux $J_{w}$ Wall mass flux

$f$ Dimensionless stream function $u_{w}$ Velocity of the wall

$K^{*}$ Mean absorption coefficient $\sigma^{*}$ Stephan-Boltzmann constant

$S h_{x}$ Sherwood number Pr Prandtl number

$(u, v)$ Velocity components in $\mathrm{x}$ - and $\mathrm{y}$-axis $R \quad$ Radiation parameter

$\tau_{w}$ Shear stress Le Lewis number

M Magnetic field parameter $D_{m}$ Diffusion coefficient

$B_{0}$ Strength of Magnetic Field Bi Biot Number

$(x, y)$ Direction along and perpendicular to the cylinder $C_{r}$ Chemical reaction parameter

Vo Suction parameter $C_{w}$ Concentration at the wall

Nr Buoyancy parameter $\alpha$ Deborah number

Greek symbols

$\beta$ Thermal relaxation number $\nu$ Kinematic viscosity

$\mu$ Fluid viscosity $\rho_{p}$ Nanoparticle mass density

$S$ Dimensionless nanoparticle volume fraction $\eta$ Similarity variable

$\theta$ Dimensionless $\sigma$ Electrical conductivity

$\lambda_{1}$ Fluid relaxation time $\lambda_{2}$ Thermal relaxation time 


\section{Subscripts}

[?] Condition far away from cone surface hnf Hybrid nanofluid

$f$ Base fluid nf Nanofluid

Superscripts

' Differentiation with respect to $\eta$

Table 1. Thermo-physical properties of nanofluids.

\begin{tabular}{lllll}
\hline Fluid & $\rho\left(\frac{\mathrm{Kg}}{m^{3}}\right)$ & $C_{p}\left(\frac{J}{\mathrm{kgK}}\right)$ & $k\left(\frac{W}{\mathrm{mK}}\right)$ & $\sigma(U m)^{-1}$ \\
\hline Pure water SWCNTs Ag & 997.1260010500 & 4179425235 & 0.6136600429 & $0.0510^{6} 6.3 \times 10^{7}$ \\
\hline
\end{tabular}

Table 2: Comparison of $\left(-\theta^{\prime}(0)\right)$ for $M=0, C r=0, \gamma=0, \phi_{1}=0, \quad \phi_{2}=0$ and fixed other parameters.

\begin{tabular}{lll}
\hline Parameter & Waini et al. [43] & Present Results \\
\hline $\operatorname{Pr}$ & $\left(-\theta^{\prime}(0)\right)$ & $\left(-\theta^{\prime}(0)\right)$ \\
2.06 .137 .020 .0 & 0.9113531 .7596821 .8954003 .353902 & $0.911341 \quad 1.7596761 .8953973 .353915$ \\
\hline
\end{tabular}

Table 3: The sway of pertinent parameter entered into the problem on skin friction coefficient $\left(-f^{\prime \prime}(0)\right)$, local Nusselt number $\left(-\theta^{\prime}(0)\right)$ and local Sherwood number $\left(-S^{\prime}(0)\right)$.

\begin{tabular}{|c|c|}
\hline Parameters & Parameters \\
\hline$\overline{\mathrm{M}}$ & $\phi 1$ \\
\hline
\end{tabular}

Table 4: The sway of pertinent parameter entered into the problem on skin friction coefficient $\left(-f^{\prime \prime}(0)\right)$, local Nusselt number $\left(-\theta^{\prime}(0)\right)$ and local Sherwood number $\left(-S^{\prime}(0)\right)$.

Parameters

$\mathrm{R}$

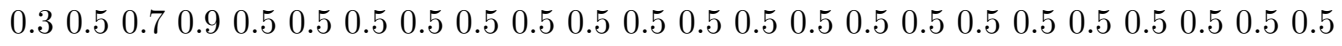

Parameters

$\operatorname{Pr}$

1.01 .01 .01 .02 .24 .26 .28 .21 .0 


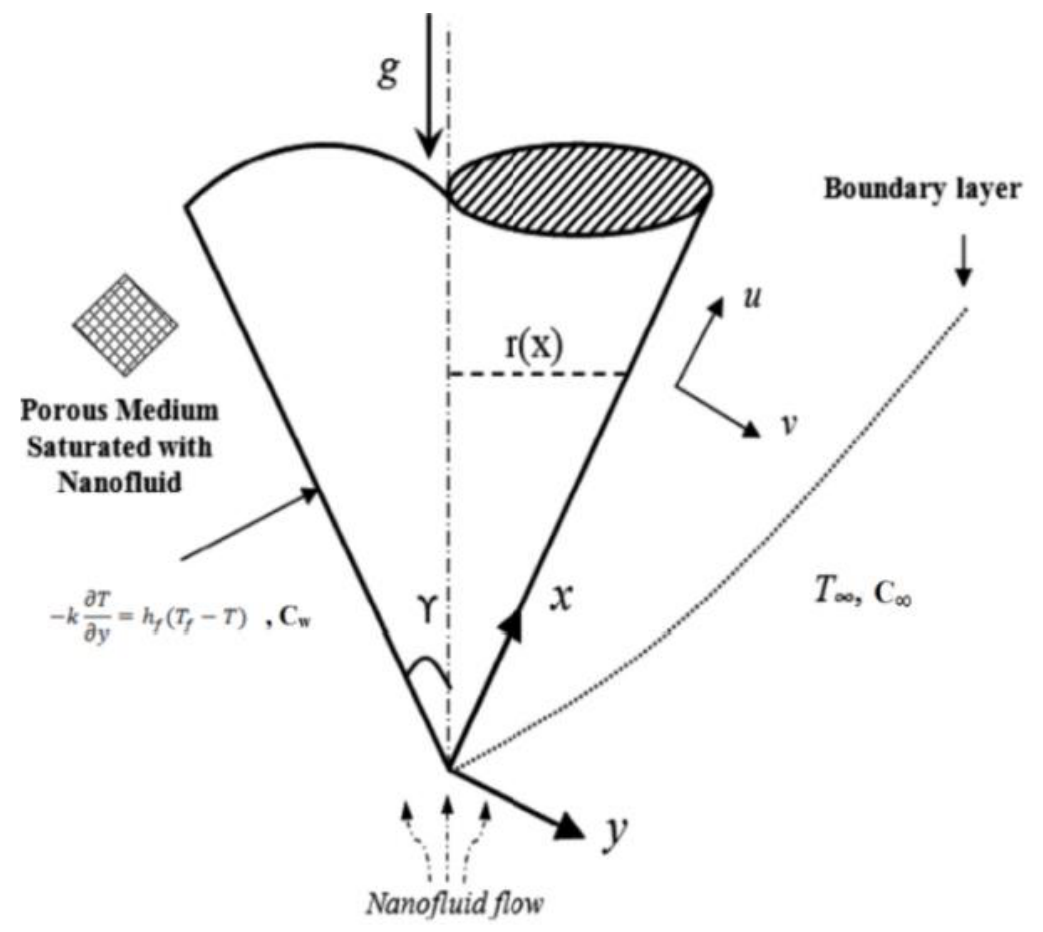

Fig. 1. Physical model and Coordinate system. 


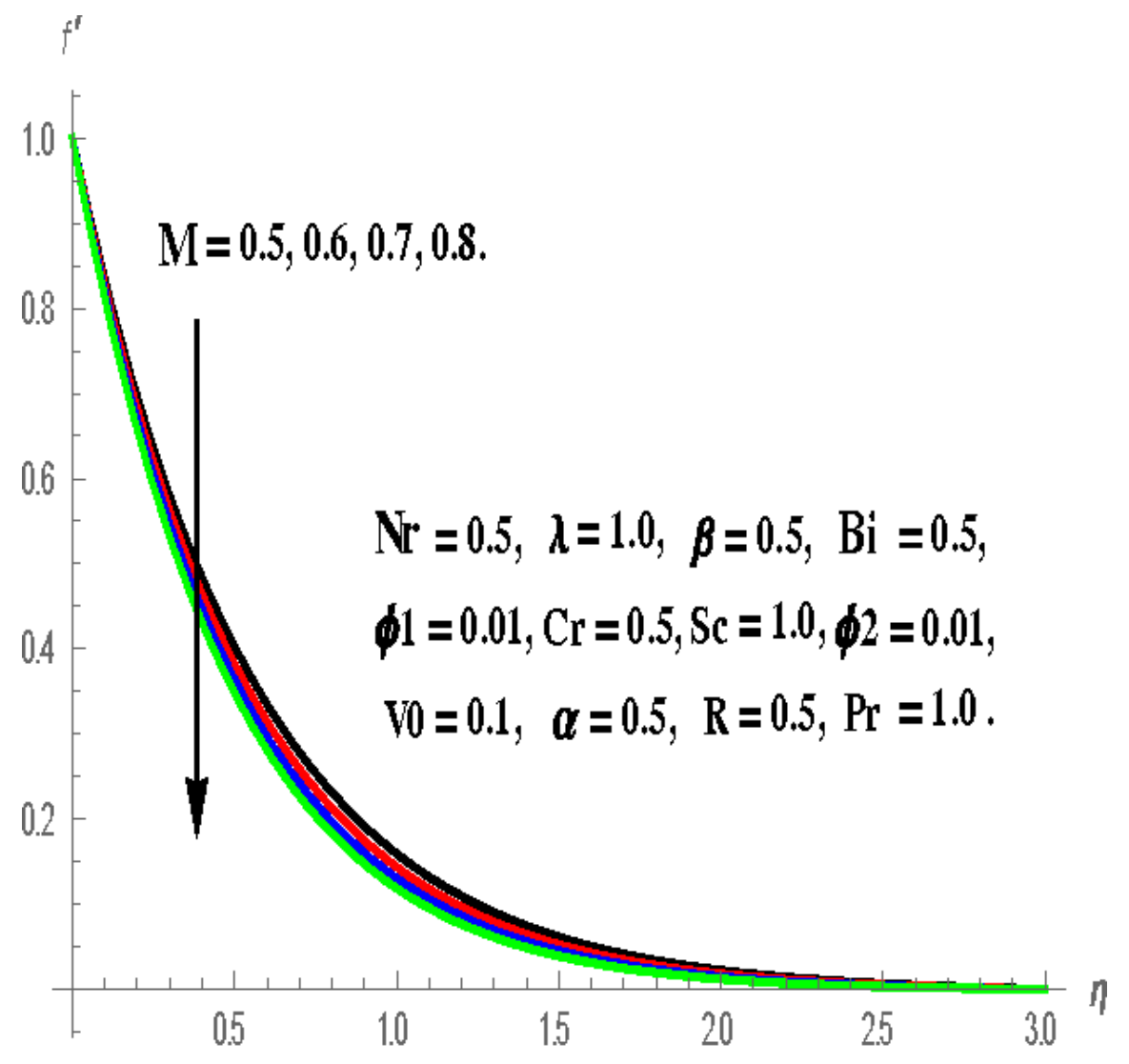

Fig. 2. Effect of (M) on Velocity profiles. 


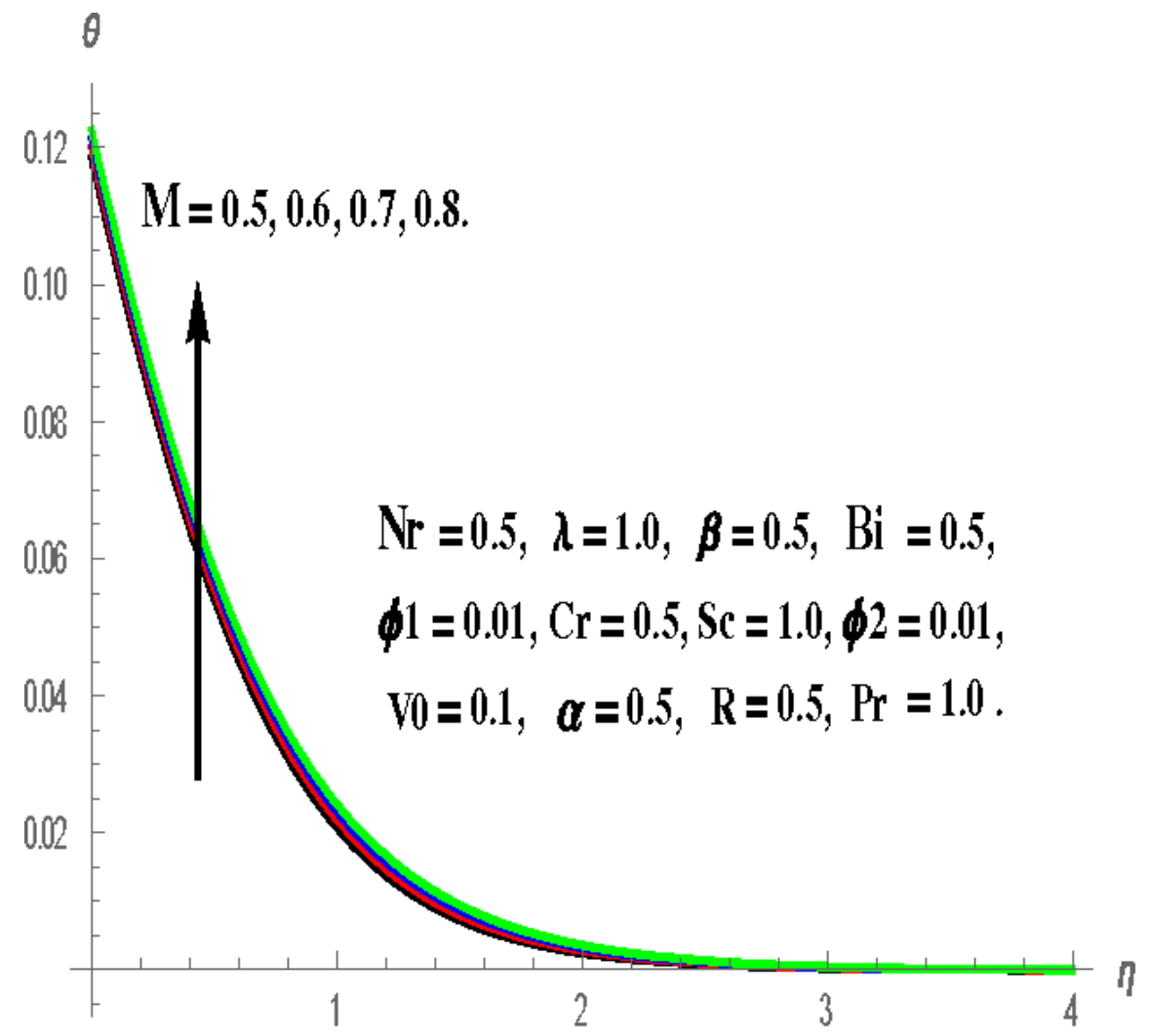

Fig.3. Effect of (M) on Temperature profiles. 


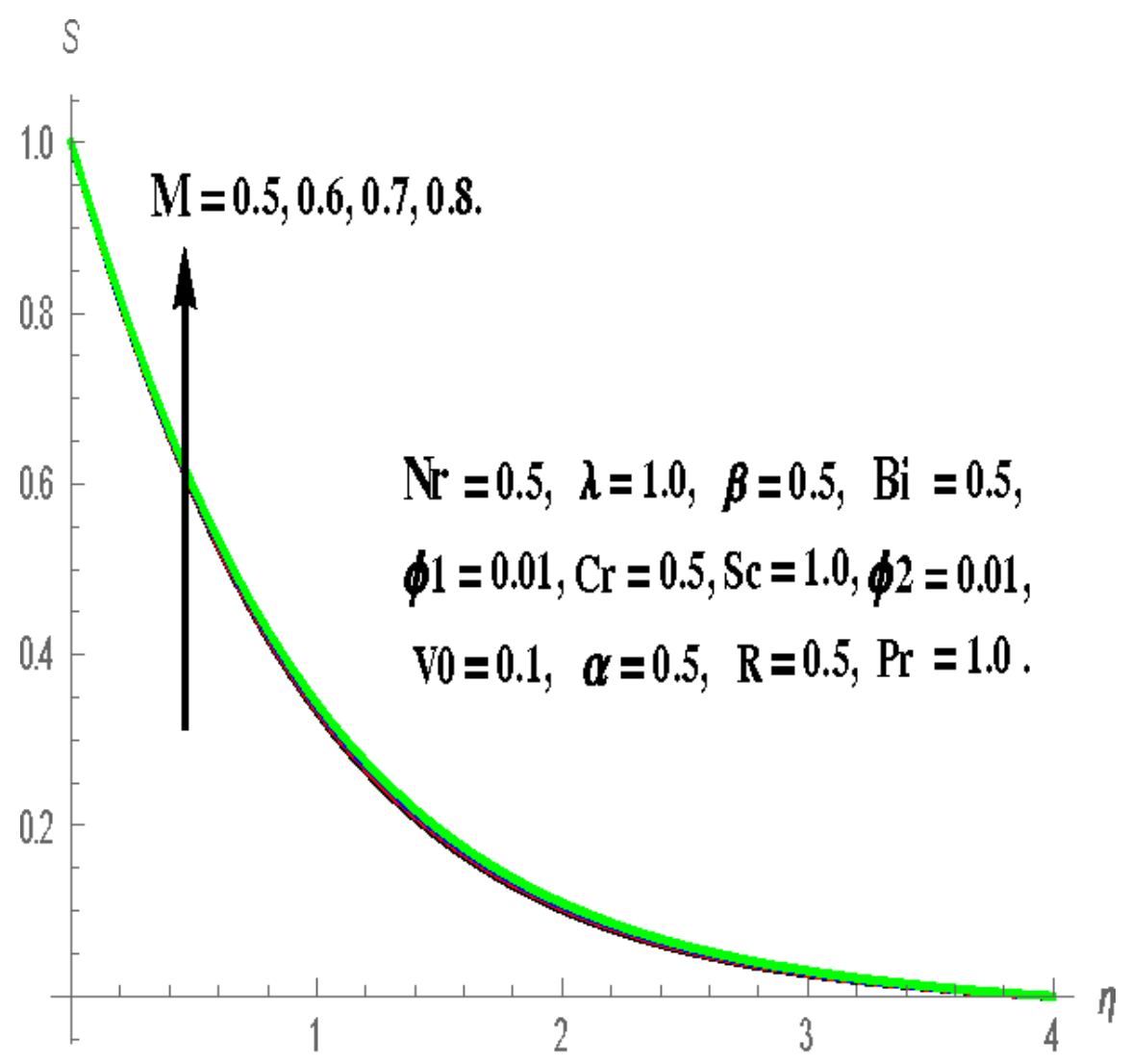

Fig.4. Effect of (M) on Concentration profiles. 


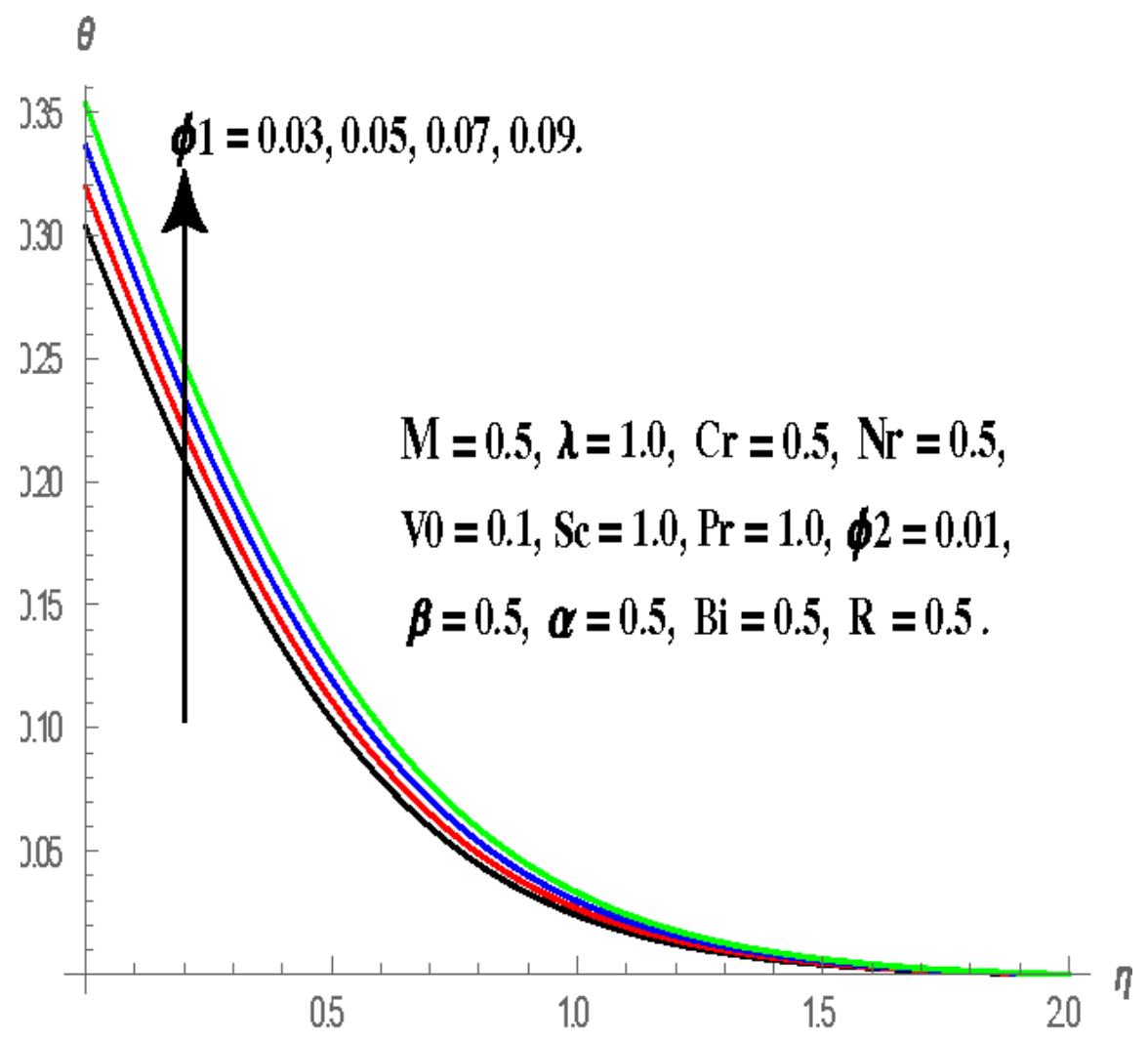

Fig.5. Effect of $(\phi 1)$ on Temperature profiles. 


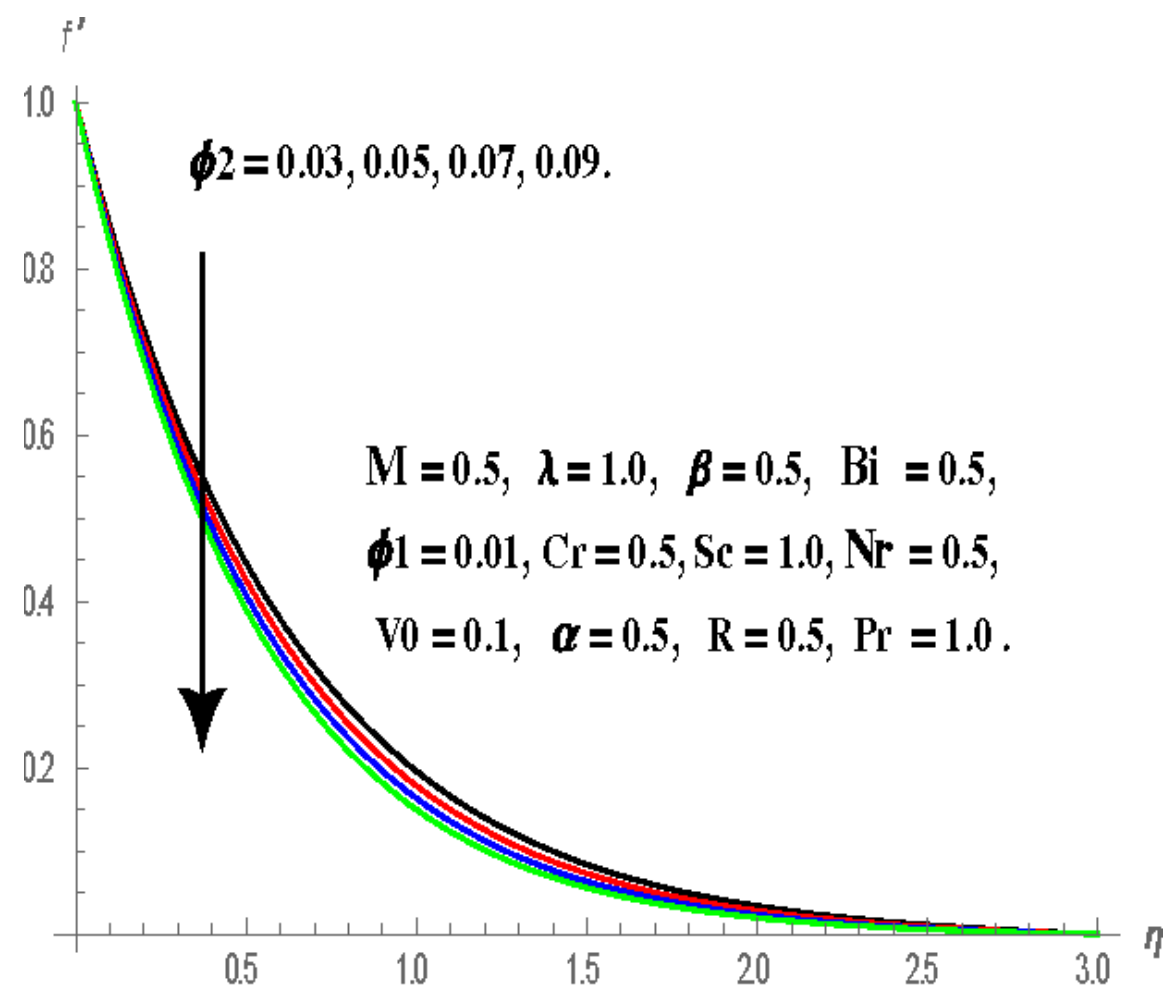

Fig.6. Effect of ( $\phi 2)$ on Velocity profiles. 


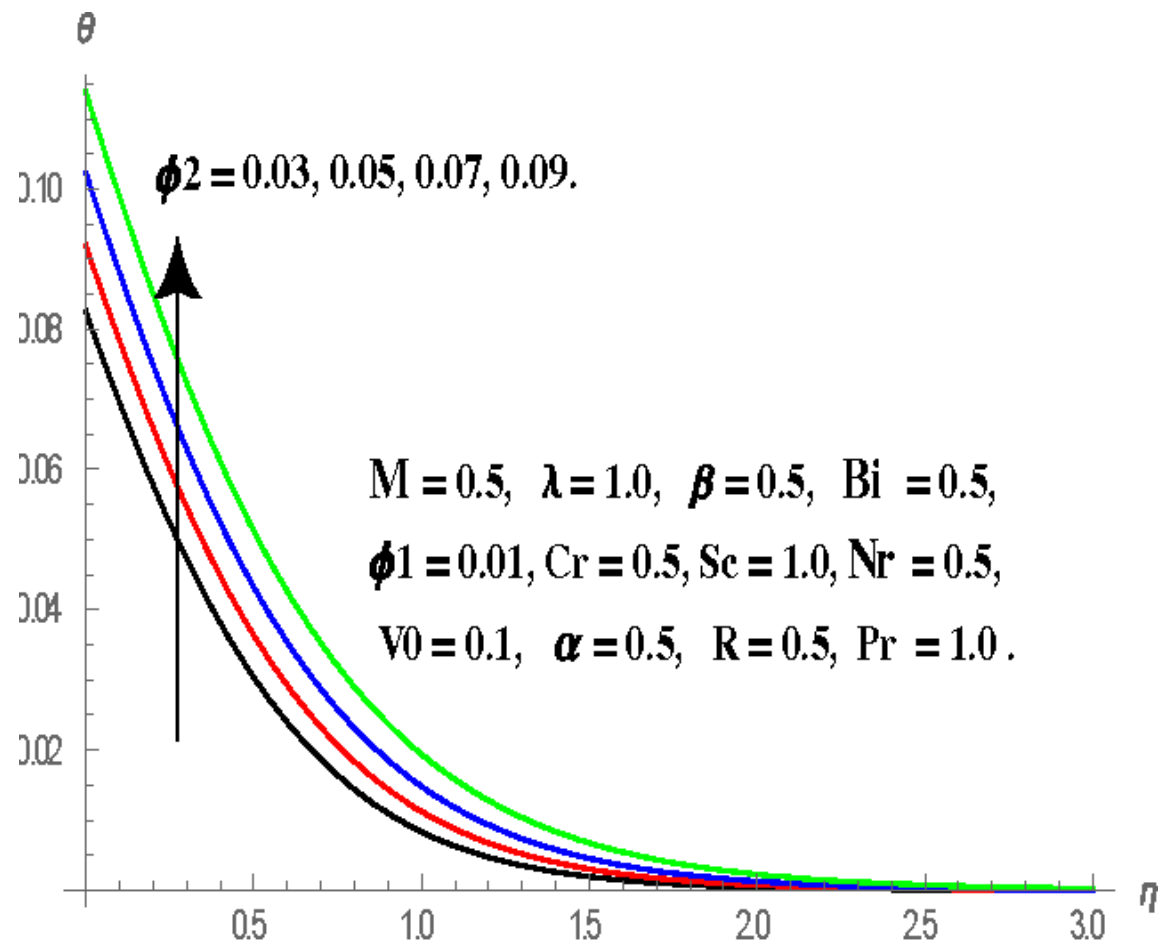

Fig.7. Effect of $(\phi 2)$ on Temperature profiles. 


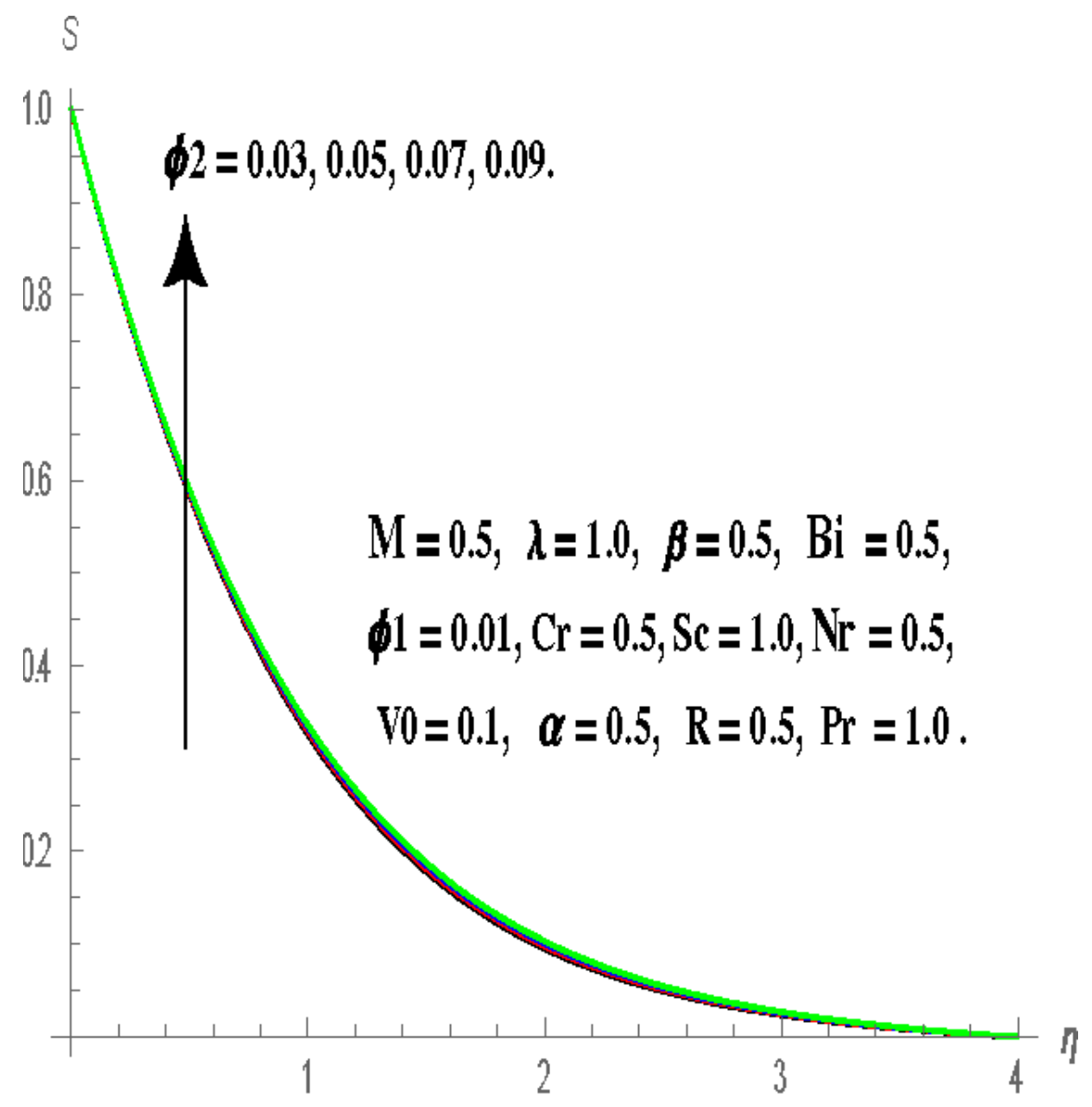

Fig.8. Effect of $(\phi 2)$ on Concentration profiles. 


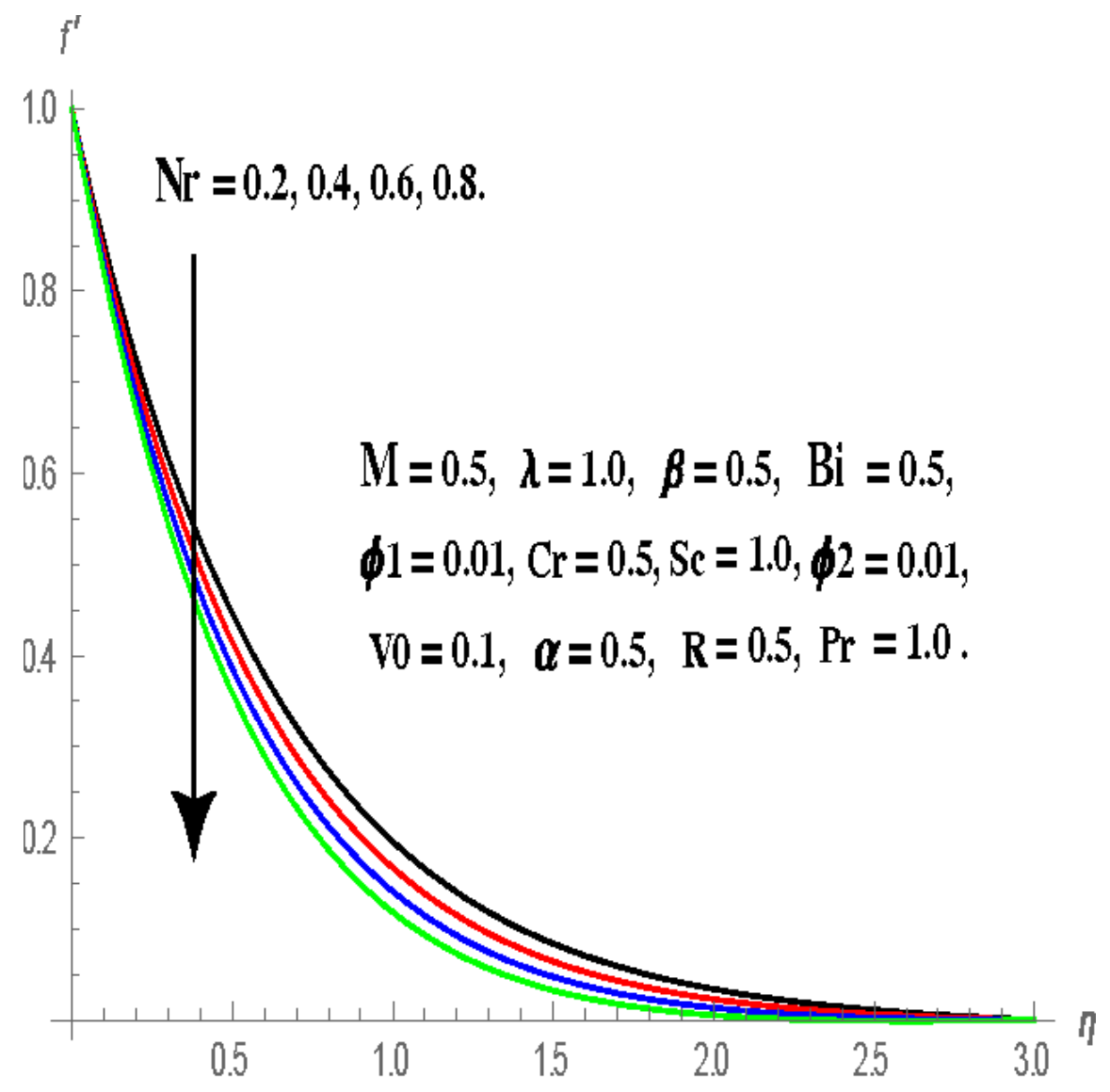

Fig.9. Effect of (Nr) on Velocity profiles. 


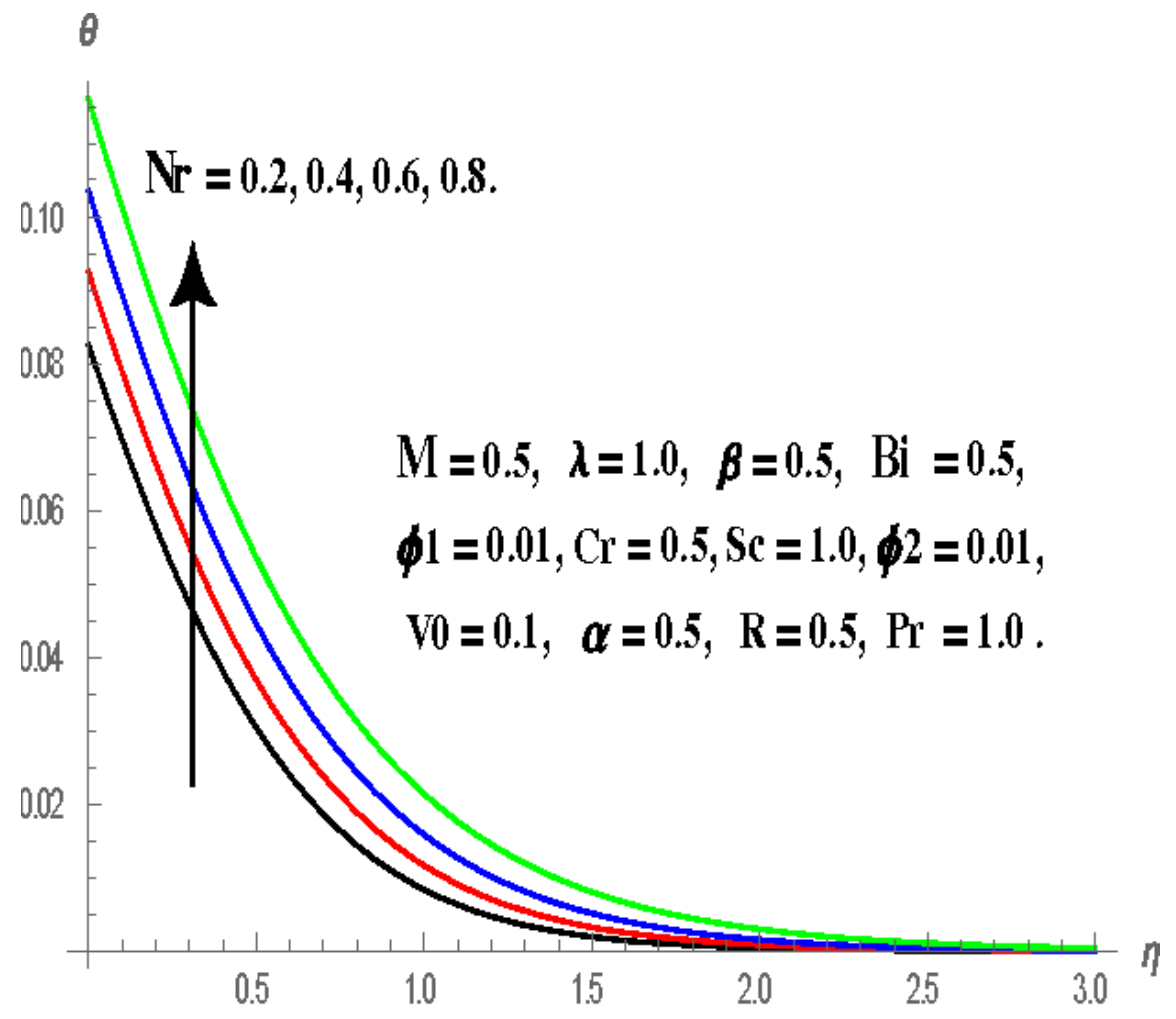

Fig. 10. Effect of $(\mathrm{Nr})$ on Temperature profiles. 


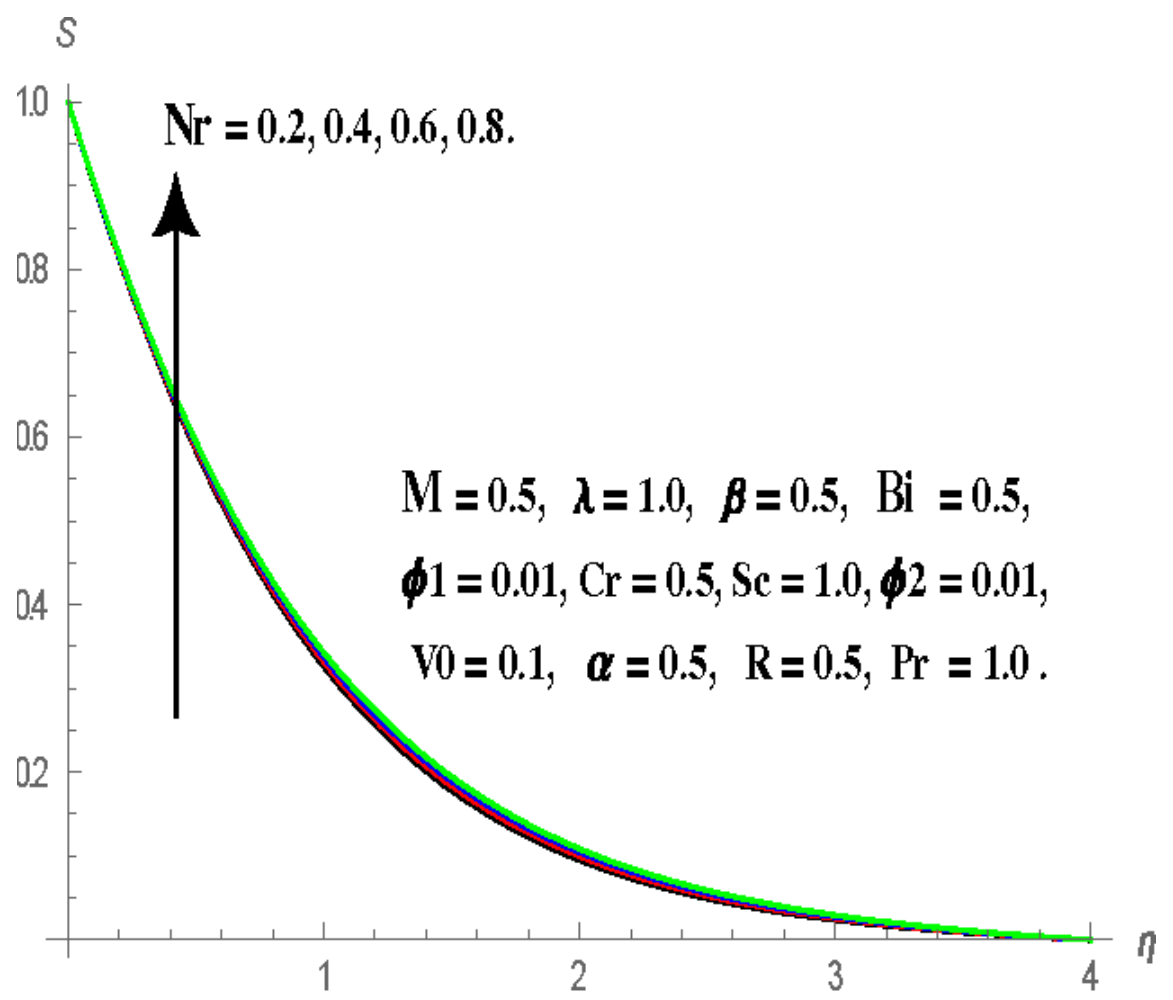

Fig.11. Effect of (Nr) on Concentration profiles. 


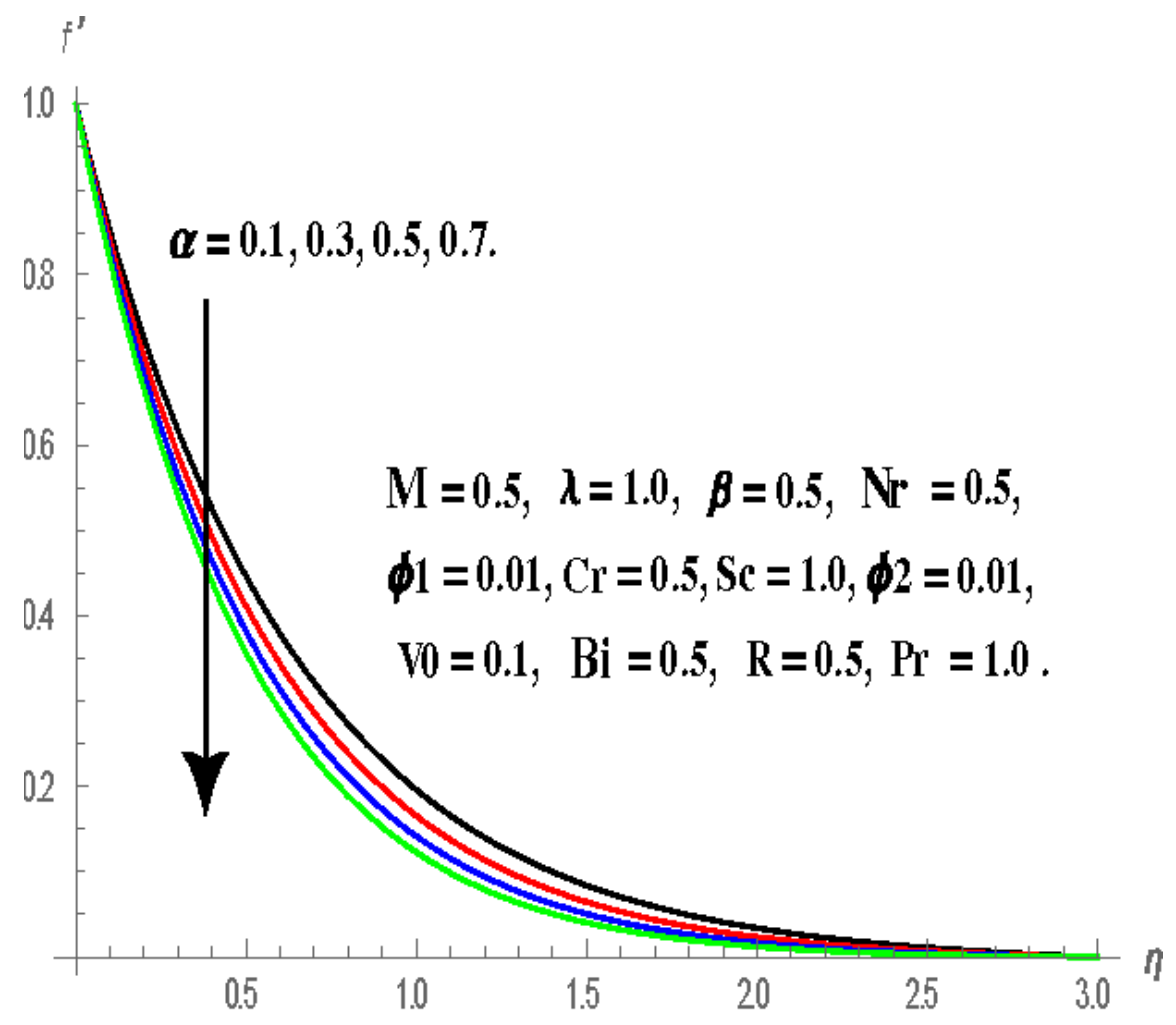

Fig.12. Effect of $(\alpha)$ on Velocity profiles. 


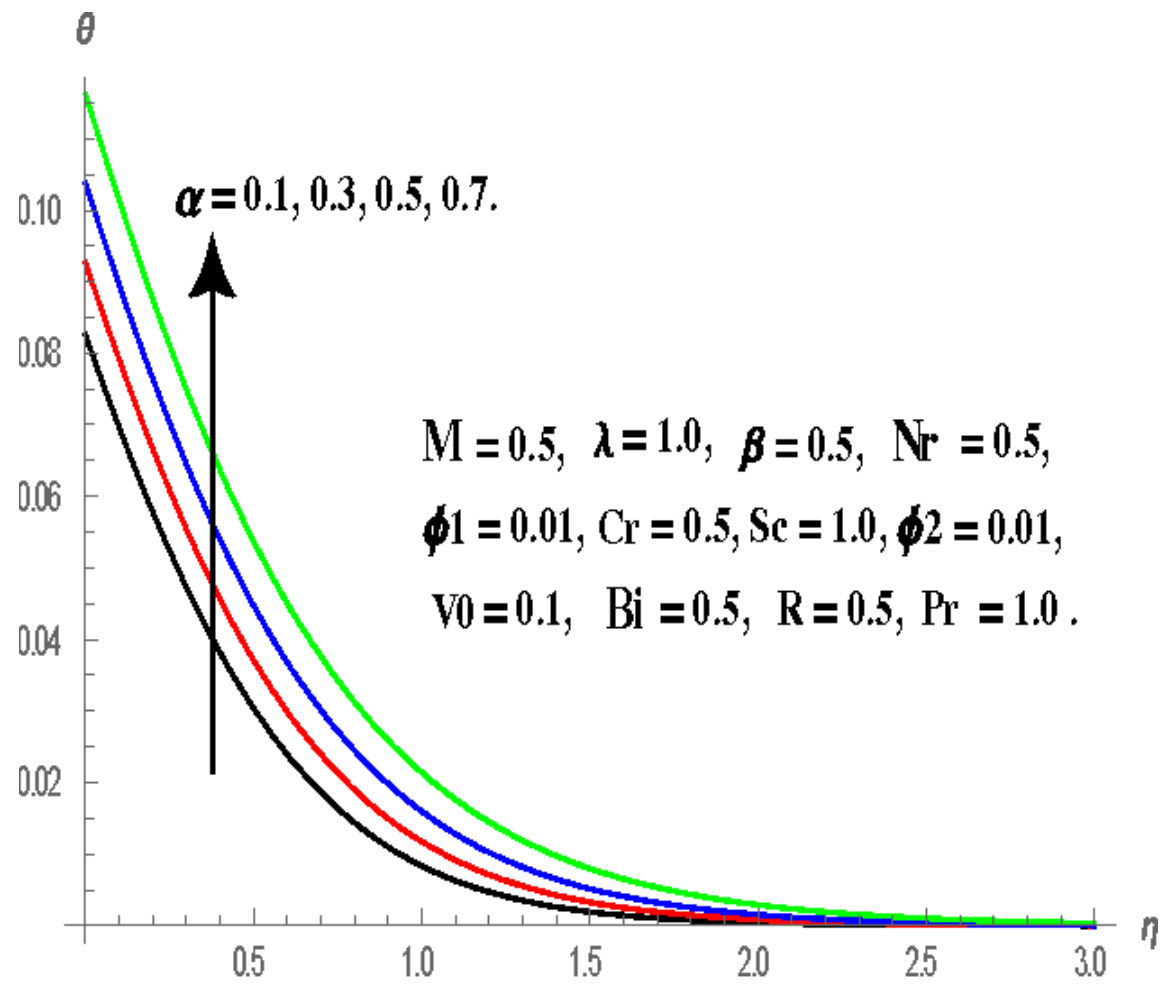

Fig.13. Effect of $(\alpha)$ on Temperature profiles. 


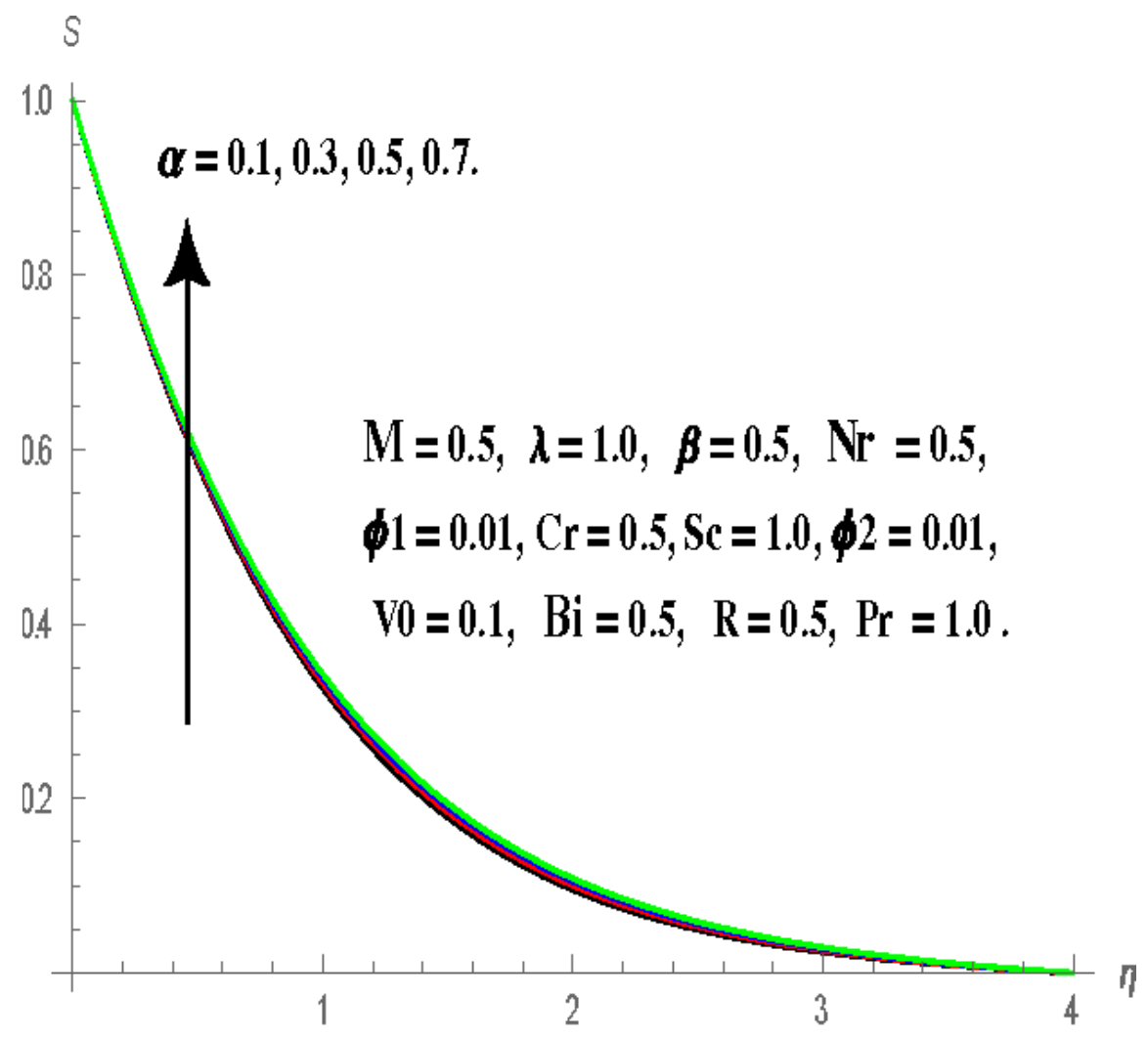

Fig.14. Effect of $(\alpha)$ on Concentration profiles. 


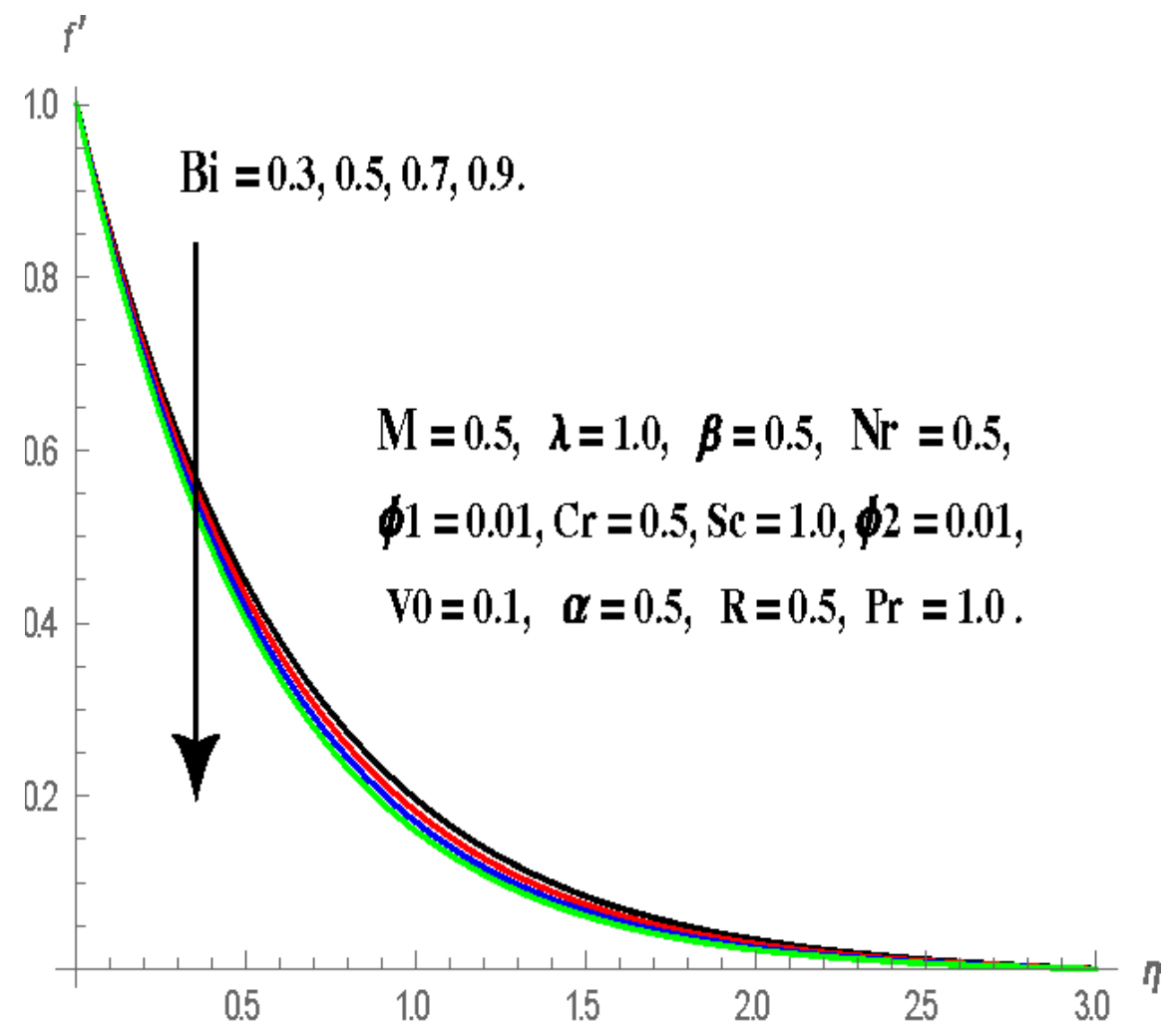

Fig. 15. Effect of (Bi) on Velocity profiles. 


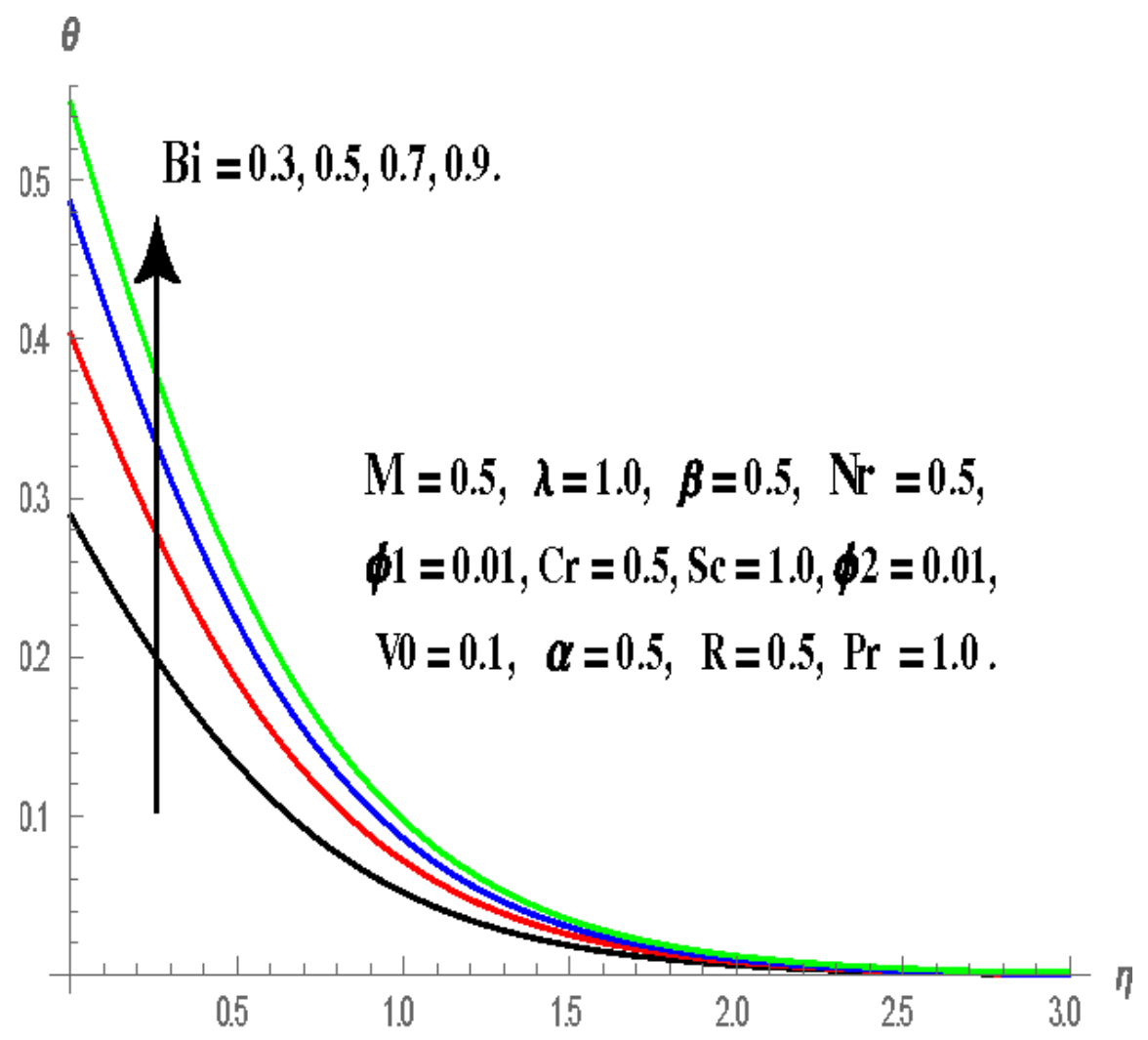

Fig. 16. Effect of (Bi) on Temperature profiles. 


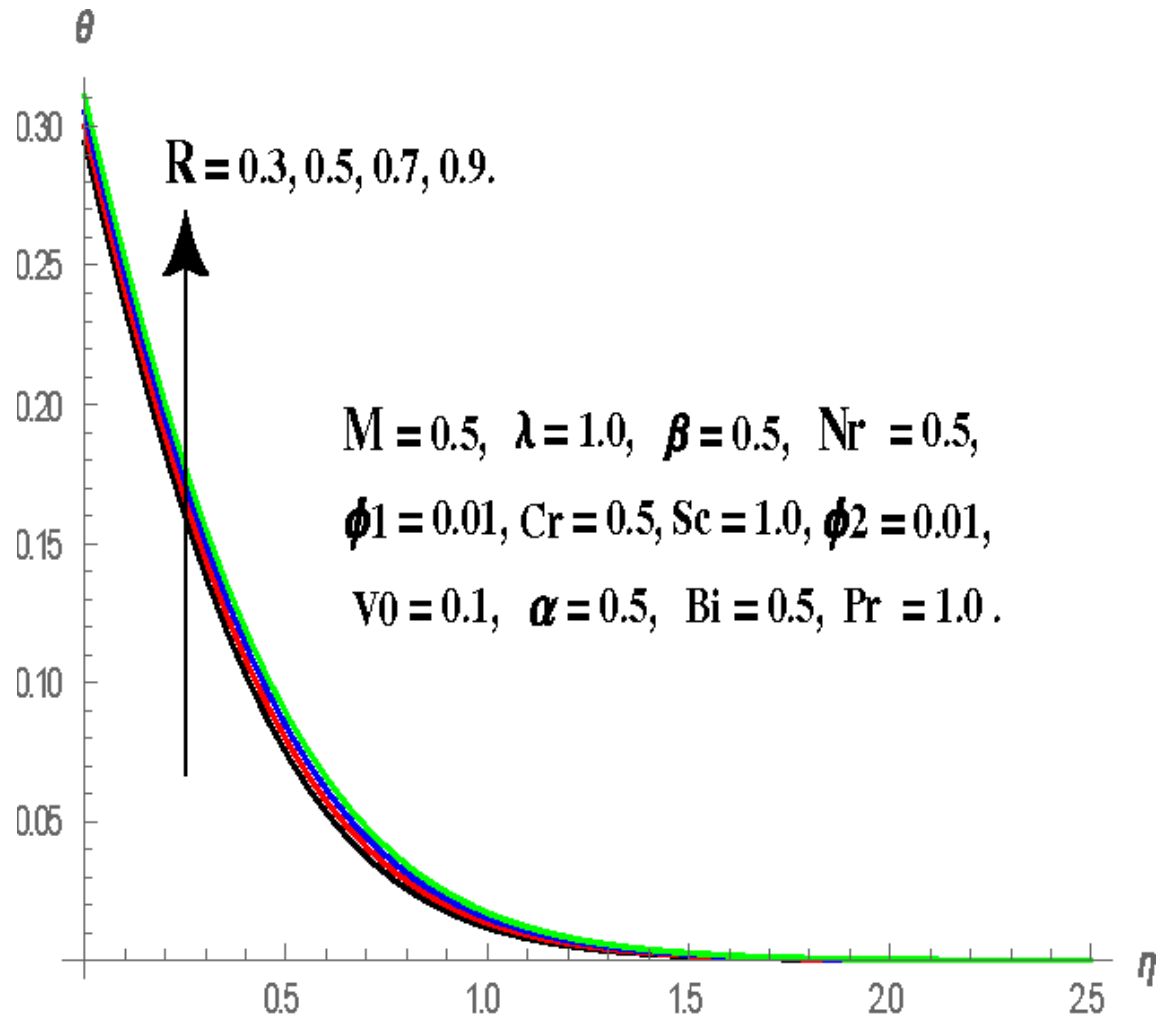

Fig.17. Effect of $(R)$ on Temperature profiles. 


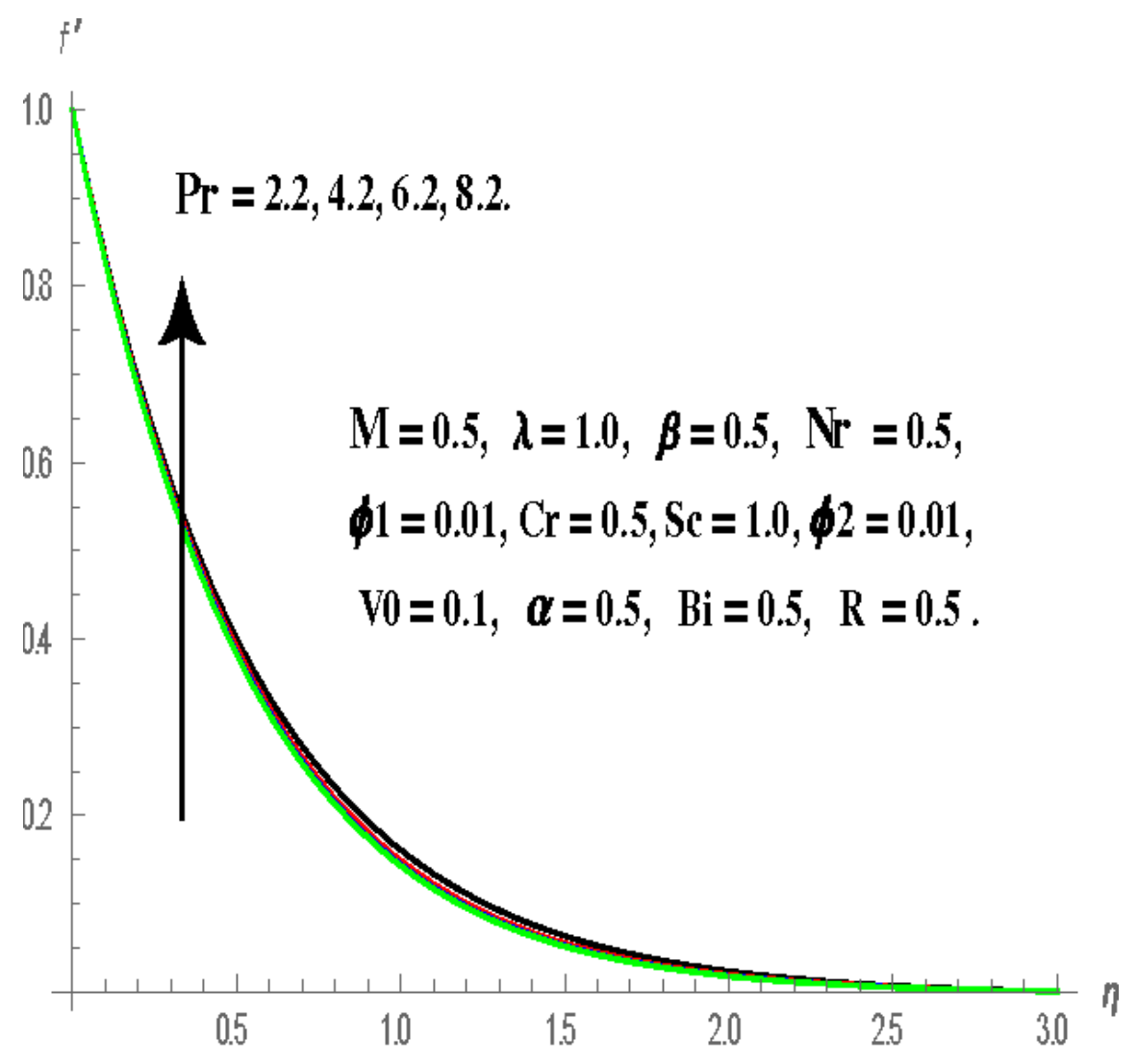

Fig. 18. Effect of (Pr) on Velocity profiles. 


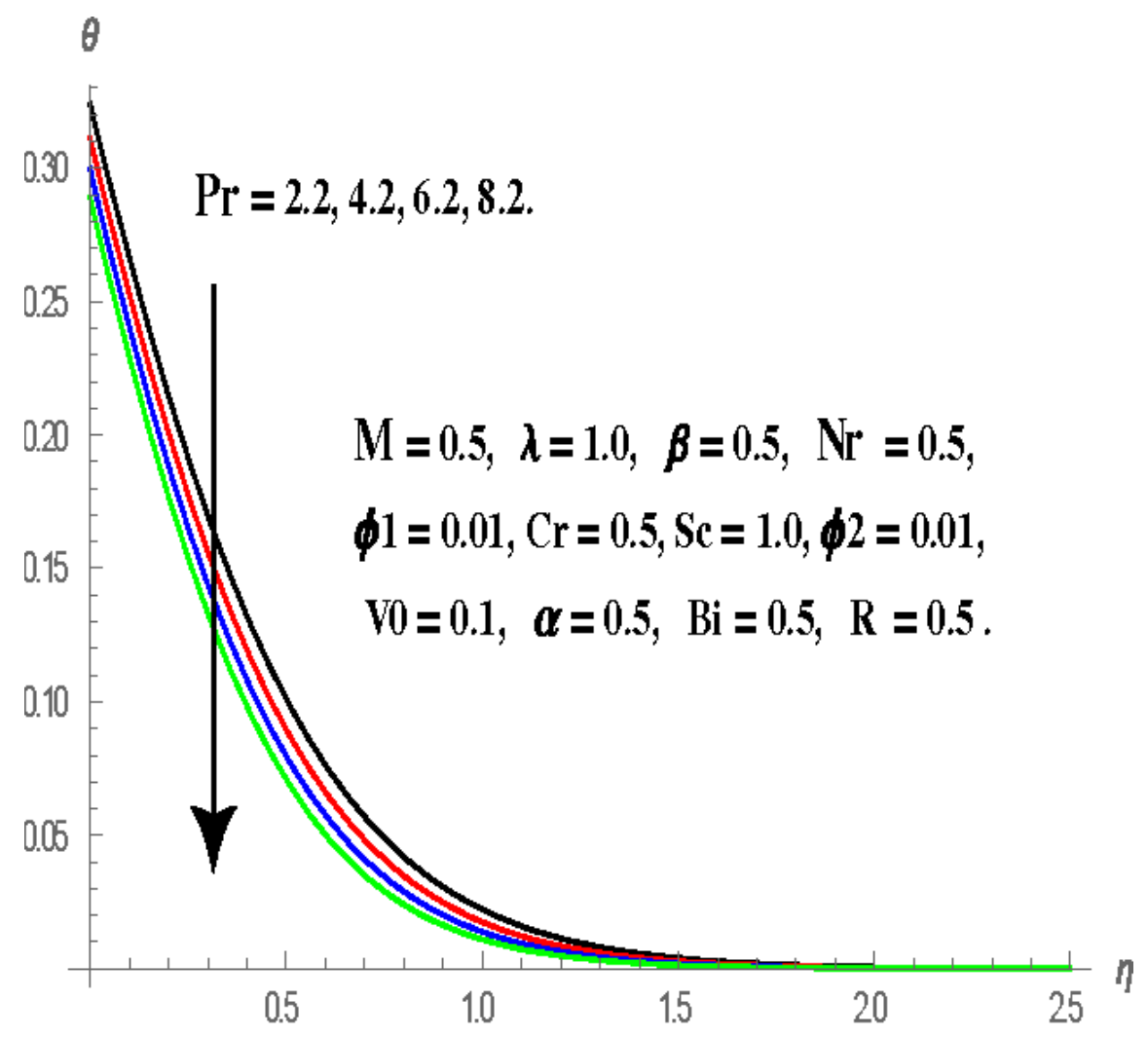

Fig.19. Effect of (Pr) on Temperature profiles. 


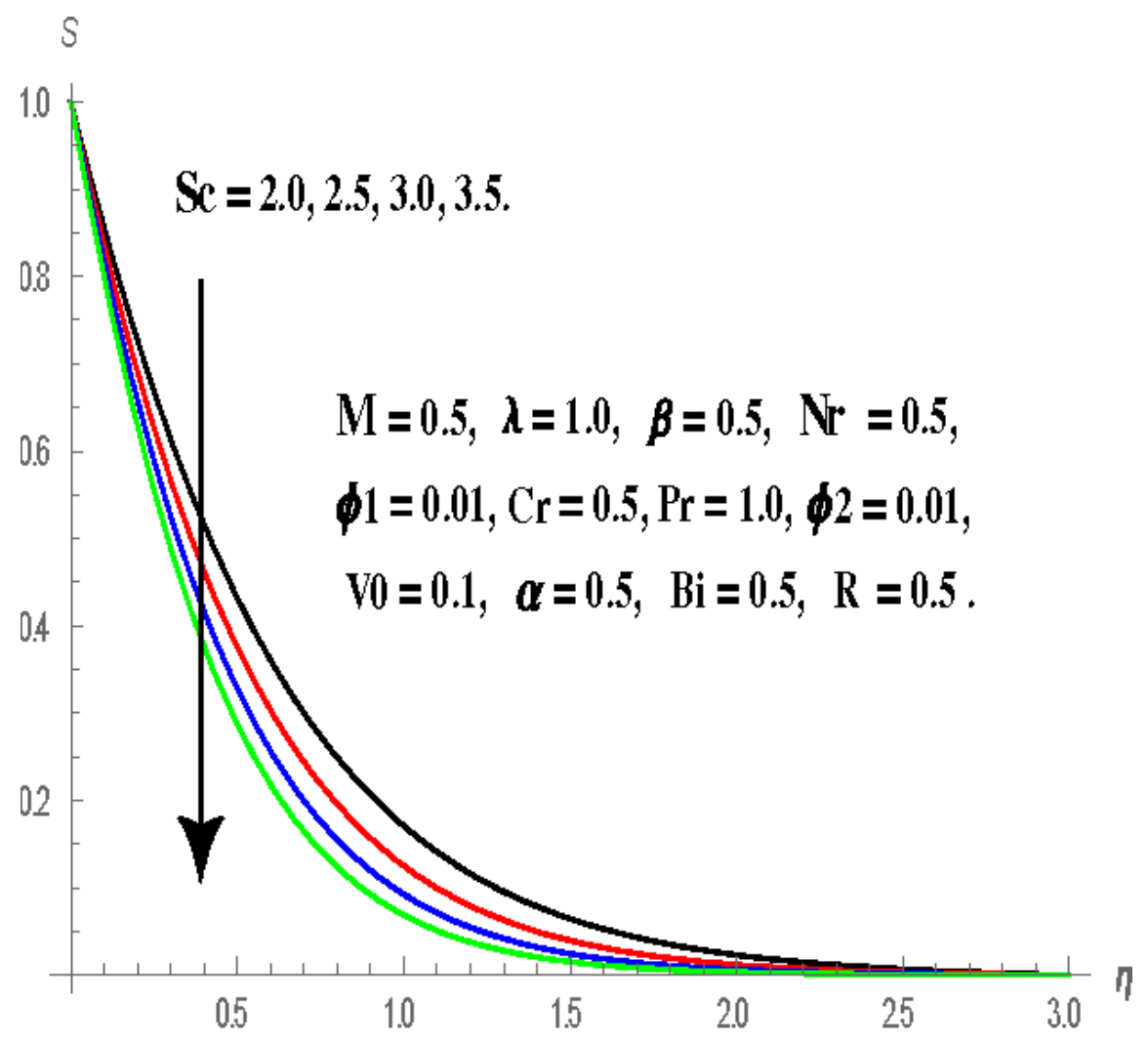

Fig. 20. Effect of (Sc) on Concenration profiles. 


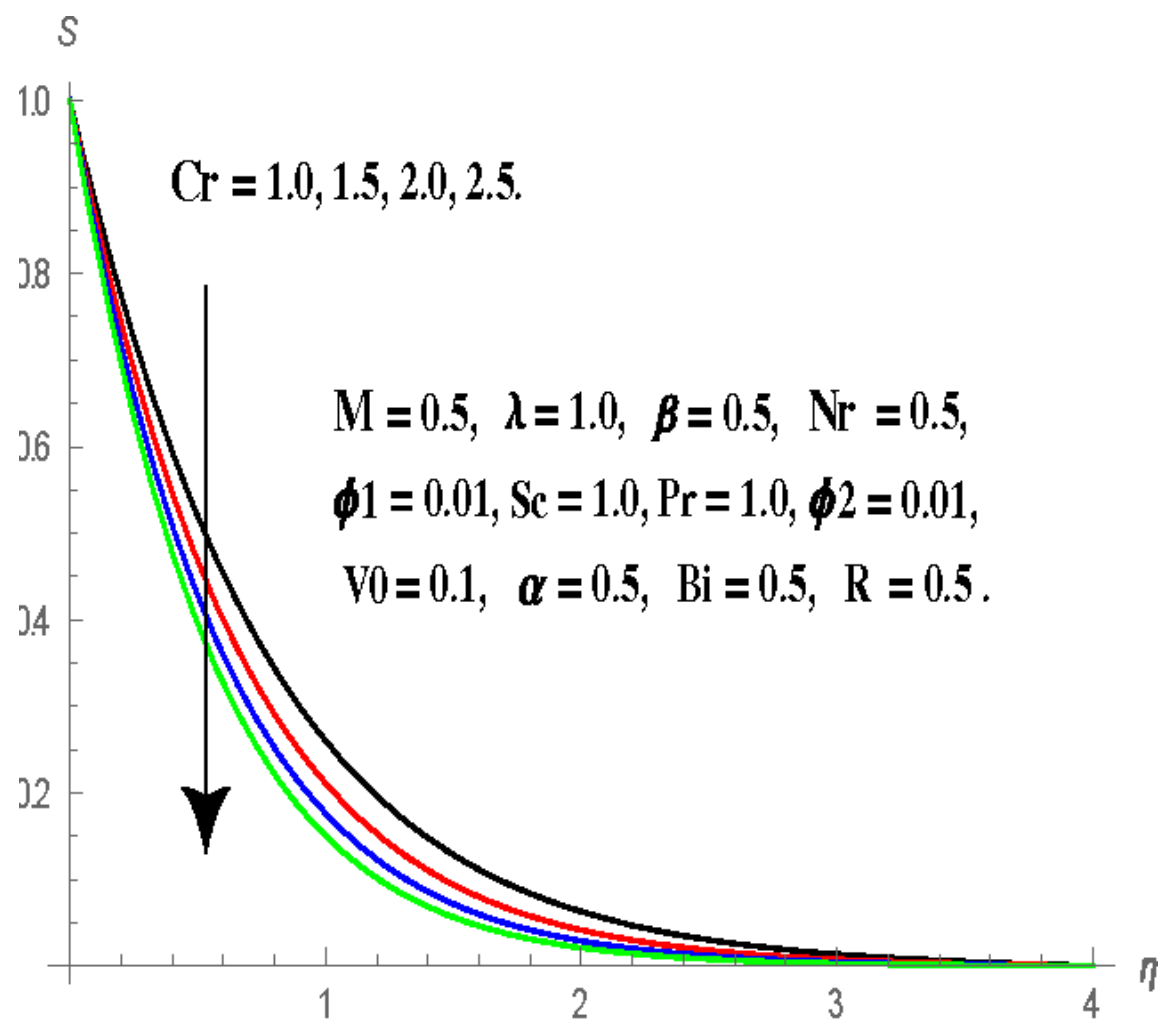

Fig.21. Effect of (Cr) on Concentration profiles. 


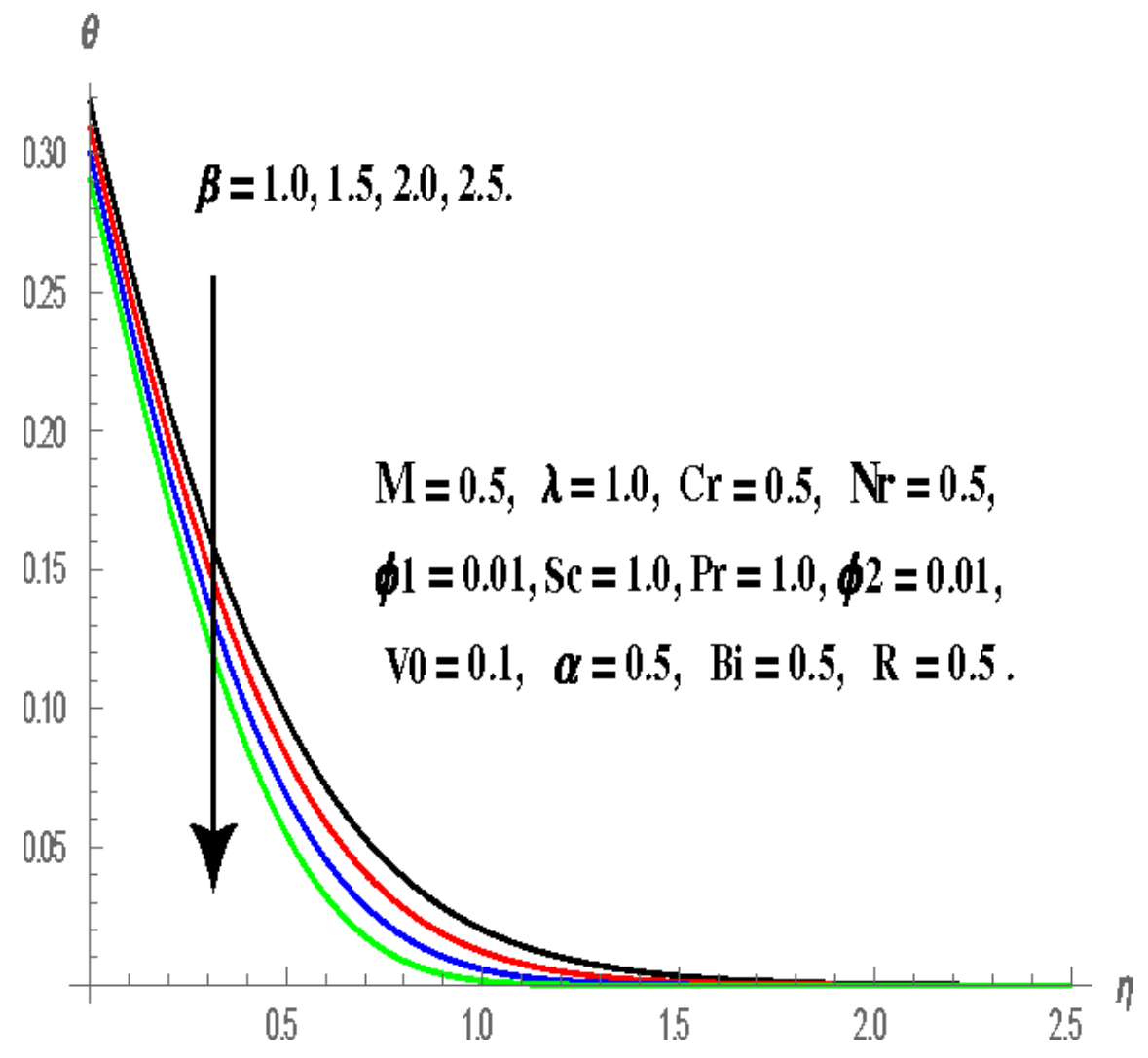

Fig.22. Effect of $(\beta)$ on Temperature profiles. 


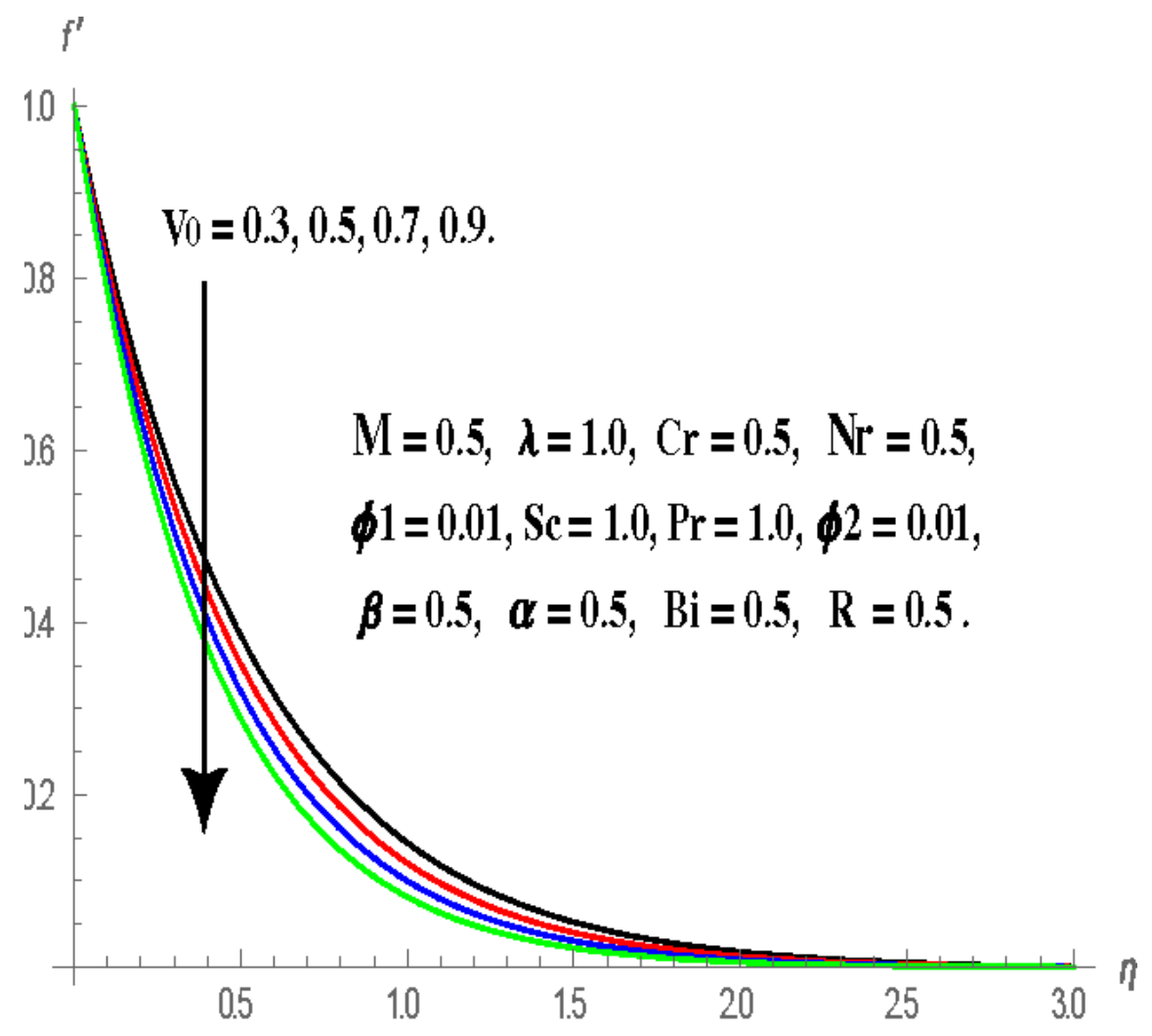

Fig.23. Effect of (V0) on Velocity profiles. 


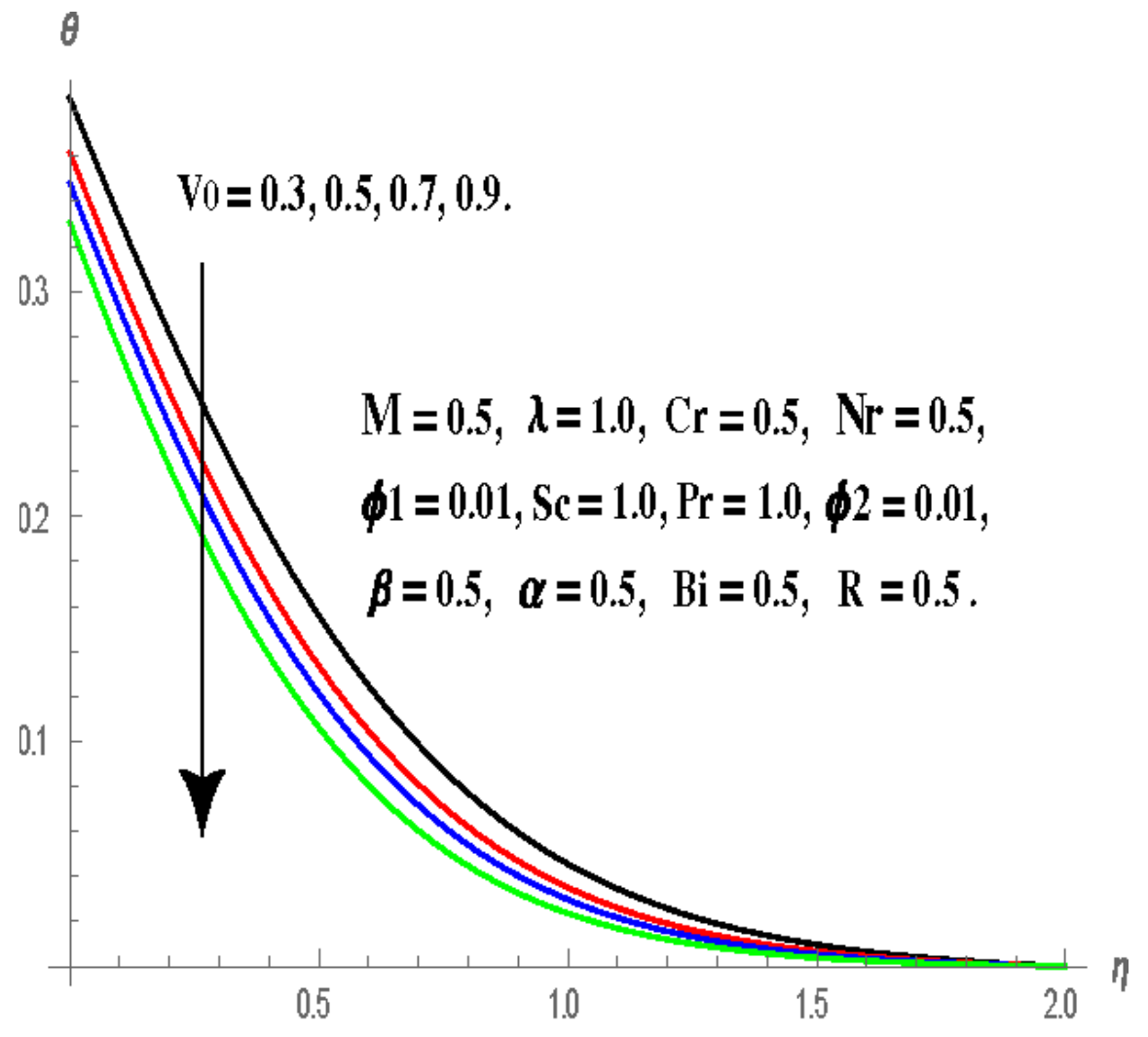

Fig.24. Effect of (V0) on Temperature profiles. 


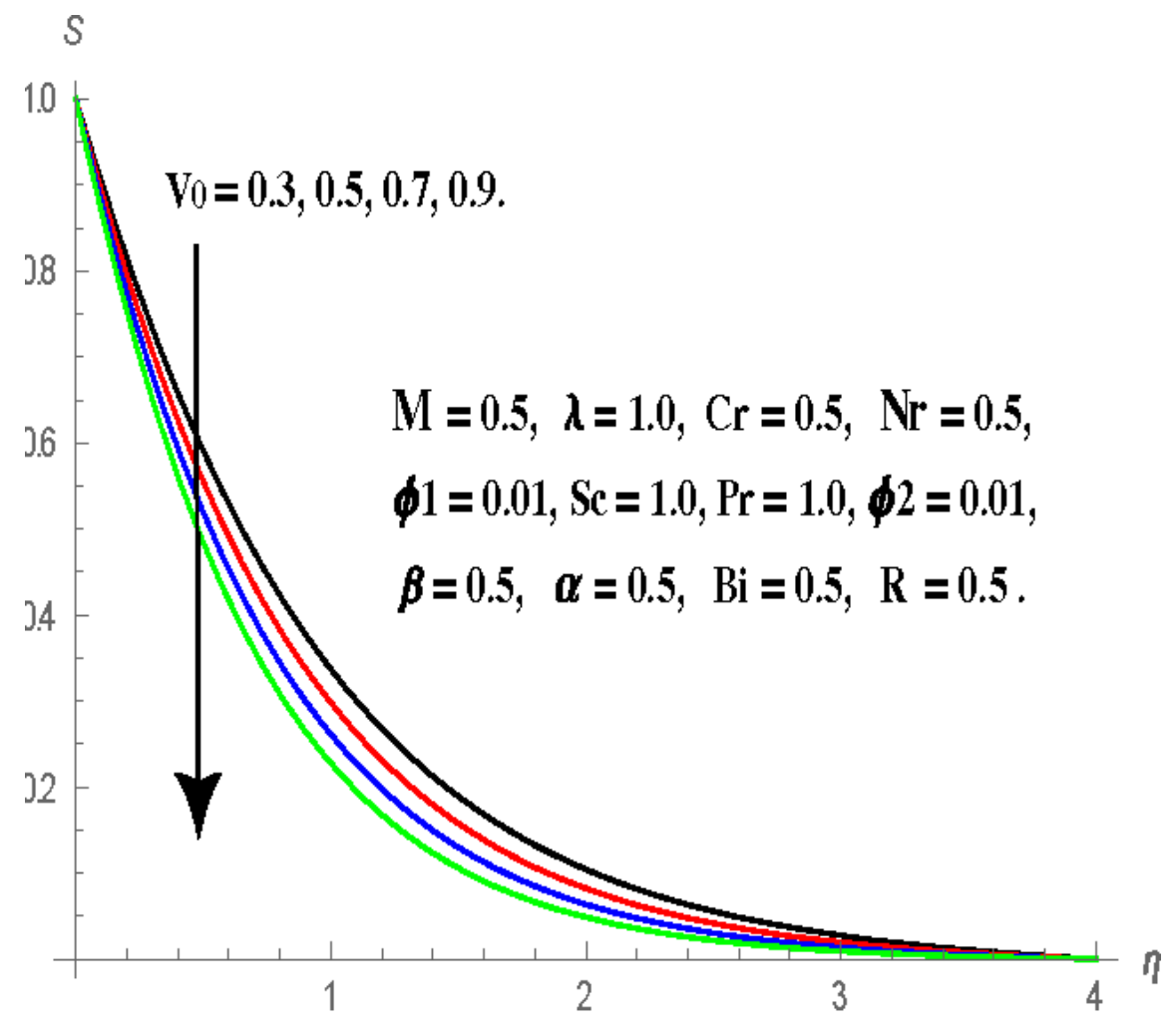

Fig.25. Effect of (V0) on Concentration profiles. 